\title{
Atmospheric Response to Mesoscale Sea Surface Temperature Anomalies: Assessment of Mechanisms and Coupling Strength in a High-Resolution Coupled Model over the South Atlantic**
}

\author{
DAVID BYRNE \\ Environmental Physics Group, Institute of Biogeochemistry and Pollutant Dynamics, and Center for \\ Climate Systems Modeling, ETH Zürich, Zurich, Switzerland \\ LUKAS PAPRITZ \\ Institute for Atmospheric and Climate Science, and Center for Climate Systems Modeling, \\ ETH Zürich, Zurich, Switzerland \\ IVY FRENGER \\ Environmental Physics Group, Institute of Biogeochemistry and Pollutant Dynamics, ETH Zürich, Zurich, \\ Switzerland, and Program in Atmospheric and Oceanic Sciences, Princeton University, Princeton, New Jersey

\section{MATTHias MÜNNICH AND NiCOLAS GRUBER} \\ Environmental Physics Group, Institute of Biogeochemistry and Pollutant Dynamics, ETH Zürich, Zurich, Switzerland
}

(Manuscript received 10 July 2014, in final form 2 December 2014)

\begin{abstract}
Many aspects of the coupling between the ocean and atmosphere at the mesoscale (on the order of 20-100 km) remain unknown. While recent observations from the Southern Ocean revealed that circular fronts associated with oceanic mesoscale eddies leave a distinct imprint on the overlying wind, cloud coverage, and rain, the mechanisms responsible for explaining these atmospheric changes are not well established. Here the atmospheric response above mesoscale ocean eddies is investigated utilizing a newly developed coupled atmosphere-ocean regional model [Consortium for Small-Scale Modeling-Regional Ocean Modelling System (COSMO-ROMS)] configured at a horizontal resolution of $\sim 10 \mathrm{~km}$ for the South Atlantic and run for a 3-month period during austral winter of 2004. The model-simulated changes in surface wind, cloud fraction, and rain above the oceanic eddies are very consistent with the relationships inferred from satellite observations for the same region and time. From diagnosing the model's momentum balance, it is shown that the atmospheric imprint of the oceanic eddies are driven by the modification of vertical mixing in the atmospheric boundary layer, rather than secondary flows driven by horizontal pressure gradients. This is largely due to the very limited ability of the atmosphere to adjust its temperature over the time scale it takes for an air parcel to pass over these mesoscale oceanic features. This results in locally enhanced vertical gradients between the ocean surface and the overlying air and thus a rapid change in turbulent mixing in the atmospheric boundary layer and an associated change in the vertical momentum flux.
\end{abstract}

\footnotetext{
* Supplemental information related to this paper is available at the Journals Online website: http://dx.doi.org/10.1175/JAS-D-140195.s1.

Corresponding author address: David Byrne, Environmental Physics Group, Institute of Biogeochemistry and Pollutant Dynamics, CHN E 23.2, Universitatstrasse 16, 8092 Zurich, Switzerland. E-mail: david.byrne@usys.ethz.ch
}

\section{Introduction}

Over the past decade, it has become clear from satellite observations that sea surface temperature (SST) anomalies associated with oceanic mesoscale phenomena, such as fronts and eddies, significantly change the overlying wind (Chelton et al. 2004; Mahrt et al. 2004; Song et al. 2006; Minobe et al. 2008; Shimada and Minobe 2011; Wallace et al. 1989; Hayes et al. 1989; 
de Szoeke and Bretherton 2004; Small et al. 2003, 2005; Putrasahan et al. 2013; O'Neill et al. 2010). Further, more recent studies show that cloud coverage and rain rate are also sensitive to these small-scale oceanic features (Park et al. 2006; Bryan et al. 2010; Frenger et al. 2013). This is remarkable given that these oceanic structures are ephemeral and range in size from tens to several hundreds of kilometers only and thus have scales that are substantially smaller than the scale of a typical synoptic atmospheric system.

Several mechanisms have been proposed to explain the observed atmospheric responses to such SST anomalies, such as 1) increased vertical mixing (Wallace et al. 1989; Hayes et al. 1989; de Szoeke and Bretherton 2004; Skyllingstad et al. 2007; Kilpatrick et al. 2014), 2) changes in boundary layer height (Samelson and Skyllingstad 2006), and 3) secondary flows in the atmospheric boundary layer driven by horizontal pressure gradients (Small et al. 2003, 2005; Mahrt et al. 2004; Song et al. 2006; Minobe et al. 2008; O'Neill et al. 2010; Shimada and Minobe 2011). However, despite a great many observational and model studies, there is no clear consensus on the relative role of the different potential mechanisms (Small et al. 2008). This lack of consensus may be due to differing atmospheric and oceanic environments of the various studies, but it is also possible that this is due to the large differences in the spatial scales of the oceanic SST anomalies considered and their relationship to the overlying conditions. For example, Spall (2007) proposed that the mechanism responsible for the change in the surface wind speed across the front depended on the background wind.

To illustrate this more explicitly, we consider the dominant terms in the atmospheric momentum balance equation, here shown for the zonal component only:

$$
U_{t}=\underbrace{-U U_{x}-V U_{y}-W U_{z}}_{\text {Advection }} \underbrace{+f V}_{\text {Coriolis Pressure gradient Mixing }} \underbrace{+\frac{1}{\rho} P_{x}}+
$$

where subscripts indicate partial differentiation; $U, V$, and $W$ are the zonal, meridional, and vertical velocities, respectively; $f$ is the Coriolis parameter; $\rho$ is the density of air; and $K_{m}$ is the coefficient for the vertical diffusion of momentum (Spall 2007). Here lateral mixing is assumed to be negligible under the assumption that horizontal scales of motion are much larger than vertical scales, and under such conditions, the horizontal turbulent fluxes are small in comparison to the dominant vertical transports. The dependence on the background wind speed becomes apparent when evaluating the length scale, over which each mechanism acts compared to the length scale of the SST front, $L_{f} \approx 10-100 \mathrm{~km}$.

The length scale over which the pressure gradient can change is predominantly determined by lateral advection and vertical mixing. Under an advective-diffusive balance assumption for temperature, this length scale is given by

$$
L_{p}=\frac{U h^{2}}{K_{T}},
$$

where $U$ is the wind speed, $h$ is the boundary layer height, and $K_{T}$ is the vertical mixing coefficient for temperature (Small et al. 2008).

Under the same advective-diffusive assumption for momentum, the equation to determine the momentumterm length scale $L_{m}$ on which the vertical mixing mechanism dominates is the same as Eq. (2), but with $K_{T}$ replaced by $K_{m}$. Typically, $L_{m}<L_{p}$ because for the same change in the mixing coefficient, the momentum term $\left(K_{m} U_{z}\right)_{z}$ changes over much smaller scales than the pressure (temperature) term, mainly because of the larger vertical gradient in wind than that of temperature. Finally, the length scale on which the Coriolis term changes is given by the Rossby deformation radius $L_{c}=U / f$.

For high-wind speed regions, such as the Southern Ocean, where the wind speed $U$ is typically $\geq 10 \mathrm{~m} \mathrm{~s}^{-1}$ and where atmospheric boundary layers are deep, that is, $h \geq 1000 \mathrm{~m}$ and $K_{T}$ is $\approx 50-100 \mathrm{~m}^{2} \mathrm{~s}^{-1}, L_{P}$ is on the order of $100-200 \mathrm{~km}$ and $L_{c}$ is on the order of $100 \mathrm{~km}$, while the length scale associated with the vertical mixing mechanism is on the order of a few kilometers, thus $L_{p} \sim L_{c} \geq L_{f} \geq L_{m}$. Hence, the length scales of the pressure adjustment and Coriolis term-driven processes are too long relative to the length scales of mesoscale SST fronts.

The situation is fundamentally different in the case of weak background wind. In equatorial regions, for example, where $U \sim 5-6 \mathrm{~m} \mathrm{~s}^{-1}$, and where boundary layers are shallow, $L_{p}$ or $L_{c}$ may become smaller than $L_{f}$, permitting the pressure anomaly and the Coriolis-based mechanism to become relevant.

Disregarding for the moment the advection term, the only process that therefore can cause SST fronts to modify the overlying atmosphere under high-wind conditions is one that involves a change in the downward flux of momentum to the surface. This mechanism is a consequence of the large temperature difference between the sea surface and the overlying air that is maintained because of the very limited ability of the atmosphere to adjust its temperature over the time scale it takes for an air mass to pass over the front.

A complication is added when one also considers the advection term. Even with high background wind 
speeds, in some cases it acts to balance the downward mixing term. In this case, it is not simply the change in the mixing term that causes the increase/decrease in surface winds, but an unbalanced Coriolis term that transfers momentum from meridional to zonal or vice versa (Spall 2007). However, Kilpatrick et al. (2014) disagree with this interpretation and show from a similar idealized model study to Spall (2007) that the perturbation to the momentum balance directly above the SST anomaly is purely between advection and the mixing term.

Finally, under conditions where background advection and the Coriolis term can be ignored, Samelson and Skyllingstad (2006) proposed another mechanism, where the increase/decrease in surface winds may be explained by a one-dimensional balance $\tau=-G h$, where $G$ is the horizontal pressure gradient. Here, for a constant pressure gradient $G$, the linear response of the wind stress is explained via an adjustment of the boundary layer height $h$.

Given the large differences in environmental background conditions encountered in most previous studies [Gulf Stream (Mahrt et al. 2004; Song et al. 2006; Minobe et al. 2008; Shimada and Minobe 2011), the Pacific equatorial fronts (Wallace et al. 1989; Hayes et al. 1989; de Szoeke and Bretherton 2004; Small et al. 2003, 2005), the Kuroshio Extension (Shimada and Minobe 2011; Putrasahan et al. 2013), the Aghulas return current (O'Neill et al. 2010; Shimada and Minobe 2011), and the Brazil-Malvinas convergence (Shimada and Minobe 2011)], it is thus not surprising that there have been as many studies emphasizing the pressure adjustment mechanisms as there have been studies arguing for increased/decreased vertical mixing as the main mechanism responsible for the wind changes. Indeed, a review of the studied conditions according to their background wind speed tends to support the scaling argument presented above (Small et al. 2008).

The majority of these published studies focused on large-scale and relatively stationary fronts, largely disregarding the much more abundant circular fronts associated with mesoscale ocean eddies. These fronts are, on average, much smaller in size, tend to live for much shorter time scales, and are transitory in nature. This poses the question of whether the insights gained on the large-scale, stationary fronts can be applied to these transient, circular fronts as well.

Frenger et al. (2013) demonstrated recently on the basis of the analysis of over $\sim 600000$ mesoscale eddies in the Southern Ocean that these fronts also have a clearly discernible impact on the overlying atmosphere. Specifically, they showed that, relative to the atmospheric variability, the eddies induce atmospheric anomalies that range from $13 \%$ to $15 \%$ for wind and cloud fraction and from $2 \%$ to $6 \%$ for the rain rate. Frenger et al. (2013) argued, on the basis of the spatial patterns of the surface wind and wind divergence associated with the eddy, that the most likely mechanism for the observed atmospheric response was increased/decreased downward mixing. Their argument was that if the mixing term is dominant, the wind divergence will be correlated with the downwind SST gradient and will show a distinctive dipole pattern located over each fontal region. Alternatively, if the pressure mechanism is dominant, one expects a monopole pattern for wind divergence centered over the SST anomaly in the center of the eddy.

Frenger et al.'s (2013) observations of a dipole structure in the wind's divergence, that is, the presumed dominance of the downward mixing mechanism, is consistent with our expectations based on the scaling arguments presented above for the Southern Ocean. Thus, one indeed expects the dominance of the mixing mechanism for smaller-scale eddies. But for larger eddies, the pressure term may become dominant. Furthermore, it is apparent that the Coriolis term cannot be ruled out by scaling arguments alone. Thus, while Frenger et al.'s observational analyses strongly support the importance of the downward mixing mechanism, their approach remains unquantitative. In addition, their arguments can be supported only partially by the scaling arguments, leaving room for alternative interpretations.

One way to overcome these limitations is to employ physical models that permit to quantitatively test the different hypotheses and to identify the physical mechanisms driving the changes. However, it is not clear whether models have the ability to correctly capture all aspects of the mesoscale coupling between the ocean and atmosphere, in terms of both the magnitude and mechanism responsible. The main problem comes from the different horizontal and vertical resolutions that determine the model's ability to accurately represent the ocean SST front while still having a well-resolved atmospheric boundary layer (Small et al. 2008). Similar to the observations, the published modeling studies have focused, in general, on large-scale fronts and have employed models that either have high horizontal resolution $(\sim 100 \mathrm{~m})$ with an underrepresented boundary layer due to poor vertical resolution or have much coarser horizontal resolution $(\sim 50 \mathrm{~km})$ but are well resolved in the vertical.

Here we aim to bridge this gap and utilize a recently developed, high-horizontal-resolution $(10 \mathrm{~km})$ coupled atmosphere-ocean regional model to investigate mesoscale atmosphere-ocean interactions in the South Atlantic. After a thorough evaluation of the model against observations, we will investigate the mechanism 
responsible for the observed changes in atmospheric quantities over mesoscale eddies.

\section{Model description}

The coupled regional atmosphere-ocean model consists of the Consortium for Small-Scale Modeling (COSMO) model (Steppeler et al. 2003) as the atmospheric component and the Regional Ocean Modelling System (ROMS; Shchepetkin and McWilliams 2003, 2005) for the ocean component. To couple the component models, we employ the Ocean Atmosphere Sea Ice Soil, version 3.0 (OASIS3) coupling software (Valcke 2013), which allows for synchronized exchange of data fields between models.

The South Atlantic domain configuration is chosen to capture the Brazil-Malvinas confluence zone, where the warm poleward flowing Brazil and the cold equatorward Malvinas currents meet. This not only produces strong SST fronts but also generates energetic mesoscale eddies that propagate with an associated warm or cold SST anomaly compared with the surrounding water (Fig. 1a).

Both the atmosphere and the ocean model utilize the same horizontal grid with rotated coordinates in reference to a north pole geographic location of $37^{\circ} \mathrm{N}, 10^{\circ} \mathrm{W}$. The model domain spans approximately $7000 \mathrm{~km} \times$ $3500 \mathrm{~km}$ and has a resolution of $\left(0.09^{\circ} \times 0.09^{\circ}\right) \approx 10 \mathrm{~km}^{2}$. The atmosphere is configured with 40 model layers in the vertical, while the ocean model has 42 vertical levels. Of particular importance for our mesoscale coupling study are the parameterizations for the atmospheric boundary layer physics. For the surface layer parameterization, we employ an updated version of the Coupled Ocean-Atmosphere Response Experiment (COARE; Webster and Lukas 1992; Fairall et al. 1996) algorithm for the calculation of the turbulent fluxes of heat, moisture, and momentum between the atmosphere and ocean. This scheme is based on covariance measurements in the warm and cold sectors of extratropical cyclones in the midlatitude North Atlantic and is therefore particularly suited for the high storm frequency of the South Atlantic region considered for this study. The COARE parameterization is used to calculate the transfer coefficients over the open ocean and the classical Louis scheme (Louis 1979) is applied over sea ice and land. For vertical turbulent transport, the model uses a standard formulation based on a traditional TKE closure at hierarchy level 2.5 (Mellor and Yamada 1974; Müller 1981).

\section{Boundary and initial conditions}

The atmospheric model is initialized with ERAInterim data, issued by the European Centre for
Medium-Range Weather Forecasts (ECMWF; Dee et al. 2011), for 1 June 2004. The ocean model is initialized from rest with initial temperature and salinity based on 30-yr-mean climatological fields from SODA (Carton and Chepurin 2000) for the month of January. The ocean model is then spun up for a 2-yr period, with surface forcing consisting of 6-hourly averaged wind stress, net heat, and freshwater fluxes derived from ERA-Interim 2004 fields. Time series analysis of the kinetic energy shows that the majority of model levels reach statistical equilibrium after $1.5 \mathrm{yr}$; however, there remains some small drift in the abyssal ocean. Since the current study is concerned mostly with ocean surface fields, we do not believe this to be a concern. The oceanic lateral boundary conditions are based on monthly $30-y r-m e a n$ climatological data from SODA.

After the spinup of the oceanic model, the two models are coupled together through OASIS, exchanging information (heat, momentum, and freshwater) at every time step $d t=60 \mathrm{~s}$. The simulation starts on 1 June 2004 and the coupled model is run for 3 austral winter months until the end of August, with the atmospheric model being forced with lateral boundary conditions derived from 6-hourly ERA-Interim data.

\section{Model evaluation}

\section{a. Automated eddy detection and eddy composite analysis methods}

To quantify the effect of an eddy on the overlying atmosphere, we compare the difference between the atmospheric variable directly above the eddy and that of the background defined by a region surrounding the eddy, and this difference is denoted hereafter as an anomaly. The method is as follows: for each identified eddy, a region of five radii surrounding the eddy is selected depending on its individual radius $R$. Mean composites are calculated from all such instances, which are scaled to a common size and rotated, such that the mean wind direction is a common axis. This rotated coordinate system allows for the characterization of the atmospheric response upwind and downwind of the front. The mean atmospheric response for each atmospheric variable is computed from all identified eddies at each time step for the total analysis time period.

We employ two automated eddy detection methods: the first is based on the Okubo-Weiss (OW) parameter (Okubo 1970; Weiss 1991), where eddies are identified from sea level height, and the second is a vector geometry (VG)-based eddy detection method such that eddies are identified based on a velocity sign reversal 


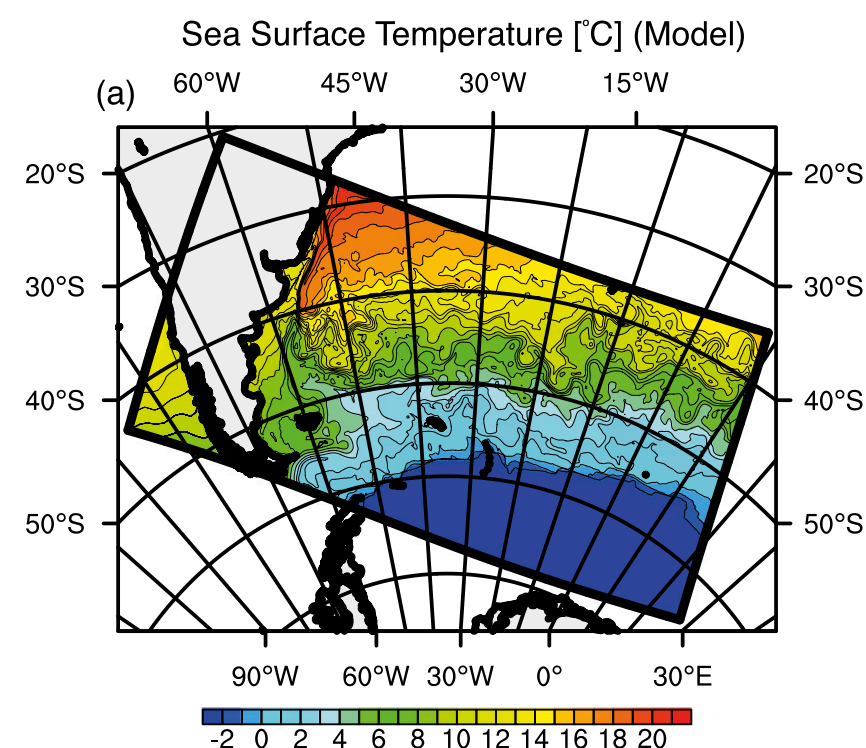

Sea Surface Temperature $\left[^{\circ} \mathrm{C}\right]$ (ERA-Interim)

(b) $60^{\circ} \mathrm{W} \quad 45^{\circ} \mathrm{W} \quad 30^{\circ} \mathrm{W} \quad 15^{\circ} \mathrm{W}$

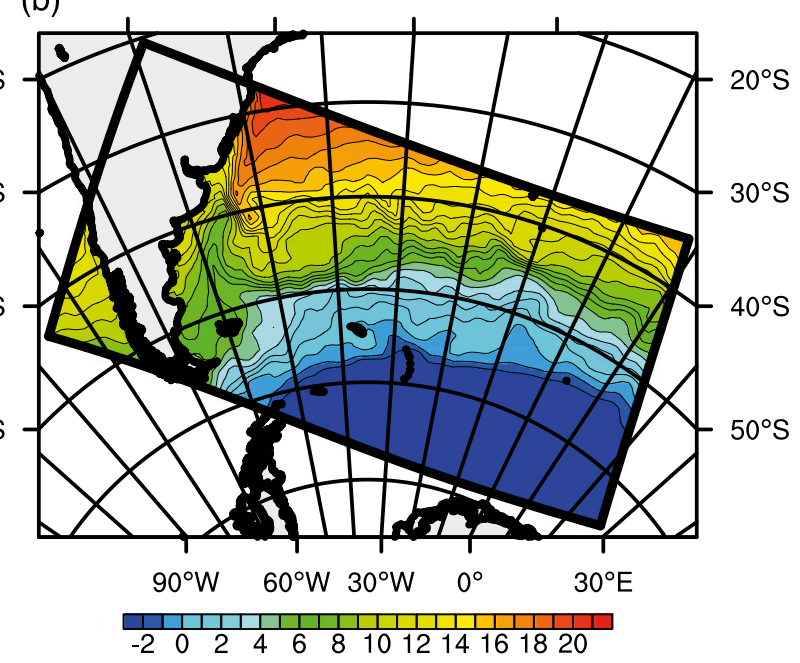

Anticyclonic Eddies (Warm SST Anomaly)
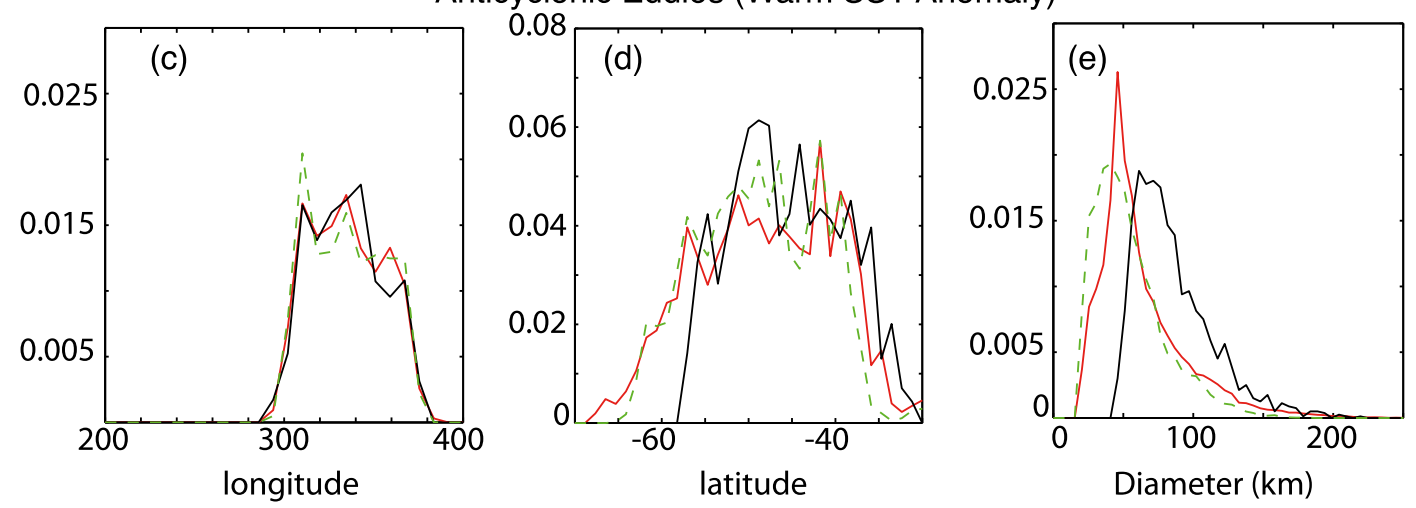

Cyclonic Eddies (Cold SST Anomaly)
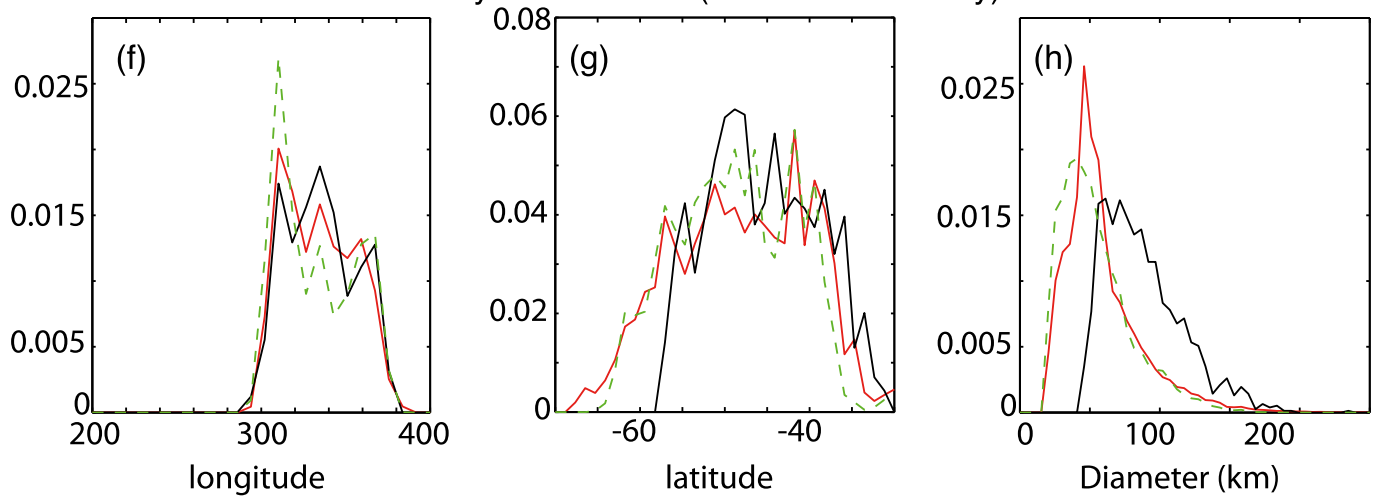

FIG. 1. (a) ROMS SST and (b) climatological SST from ERA-Interim. (c)-(h) Probability density functions of detected location and eddy diameter comparison with satellite observations (black) and model with VG (red) and OW (green dashed) eddy identification methods for anticyclonic (warm SST anomalies) and cyclonic (cold SST anomalies).

across a central minimum in both the north-south and east-west directions (Nencioli et al. 2010). The OW method is the most widely used and offers a high success of detection rate (SDR; $\sim 100 \%$ ) when compared to when eddies are manually detected, but it also suffers from overdetection with the excess of detection rate (EDR; $\sim 70 \%$ ). On the other hand, the VG-based method offers a lower SDR of $\sim 50 \%$, but also to its advantage is a much lower EDR of $\sim 6 \%$ (Yi et al. 2014). Therefore, both methods have advantages and 
disadvantages when one computes eddy composites of atmospheric variables from each identified eddy. While OW ensures the sampling of all eddies within the field, the background noise is also increased, and this may change the magnitude of the computed anomaly. In contrast, VG offers a much more accurate regime in which to compute anomalies, but it suffers from undersampling of the field. By contrasting both methods, we are able to identify any biases introduced into the anomaly calculation by the eddy detection method chosen.

Composites and anomalies from satellite observations for oceanic and atmospheric variables are calculated for the same domain and analysis time period (austral winter 2004) as the coupled model configuration (Fig. 1a). Here eddies are identified from weekly sea level height (AVISO), using the Okubo-Weiss detection scheme (Okubo 1970; Weiss 1991) and anomalies are computed from identified eddies, collocated with satellite-derived data, SST, liquid cloud water, and rain rates from AMSR-E, wind speeds from SeaWinds on QuikSCAT, and cloud fraction from GlobColour [see Frenger et al. (2013) for details]. For direct comparison with satellite observation data, we also utilize the OW detection scheme in the coupled model, but for comparison we also apply the VG-based eddy detection algorithm with mean eddy composites and anomalies computed from 6-hourly model output fields.

\section{b. Ocean}

The winter seasonal average ROMS-simulated SST represents the ERA-Interim SST well (Figs. 1a,b). The confluence zone between the Brazil and Malvinas currents is accurate in position. However, the tip of the Brazil tongue is approximately $1.5^{\circ} \mathrm{C}$ warmer than the ERA-Interim suggests. Furthermore, the cold Malvinas current does not have the same width. While this may result in increased temperature anomalies compared with the background SST in the area in the immediate vicinity, for the majority of the analysis region, eddies propagate in a reasonably represented background SST.

At any one time, numerous cyclonic and anticyclonic eddies of varying diameter $(20-200 \mathrm{~km})$ inhabit the domain and modulate the SST. Over the 3-month analysis period, $\sim 3000$ eddy instances are identified by applying the Okubo-Weiss method to satellite-derived data, where one type, warm or cold, does not dominate, with $\sim 1500$ instances each. Indeed, the statistics produced from the model are much higher because of a much higher temporal resolution, 6 hourly compared with weekly, with model eddy instances being at least a factor of 24 higher plus the addition of smaller detected eddies,

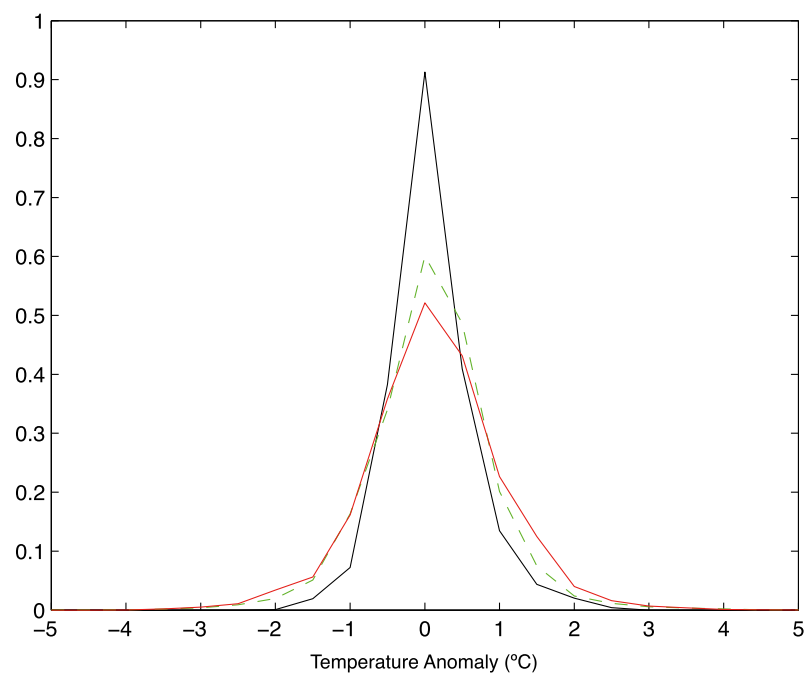

FIG. 2. Probability density function of temperature anomalies. Model VG (red) and OW (green dashed) compared with satellite observations of OW-tracked eddies (black).

$\sim 110000$ for Okubo-Weiss and $\sim 78000$ when the vector geometry algorithm is applied. In agreement with $\mathrm{Yi}$ et al. (2014), the VG-based method detects far fewer eddies than OW. Comparison of the normalized probability density functions for warm and cold eddy locations for satellite (black lines) and for the coupled model (OW, green dashed lines; VG, red lines) shows that eddies are distributed fairly evenly across the domain, and while the detected eddy numbers differ, the distributions are relatively similar (Figs. 1c-h).

While the model-normalized PDF of eddy diameter is skewed toward smaller eddies $(<50 \mathrm{~km})$ compared to the satellite, because of the model's higher spatial resolution, in terms of detected eddy numbers, the larger-scale eddies $(>50 \mathrm{~km})$ are still well represented, where both $\mathrm{OW}$ and VG detection have similar distributions for larger eddies $>50 \mathrm{~km}$; Figs. 1e,h; see supplementary material for nonnormalized histograms).

The eddy-associated SST anomalies are somewhat less well captured. The probability density function of the magnitude of the warm or cold SST anomalies associated with eddies, computed compared with the background mean SST through which they propagate, is broadened in ROMS (Fig. 2). As the response of the atmosphere above SST anomalies is linear (see below), we do not believe this broadening to be an issue. Thus, considering the consistency of the distributions, the ROMS-simulated eddy field provides a realistic SST modulation with which to test the atmospheric response.

\section{c. Atmosphere}

The general large-scale atmospheric state is predominantly determined by the lateral boundary forcing 


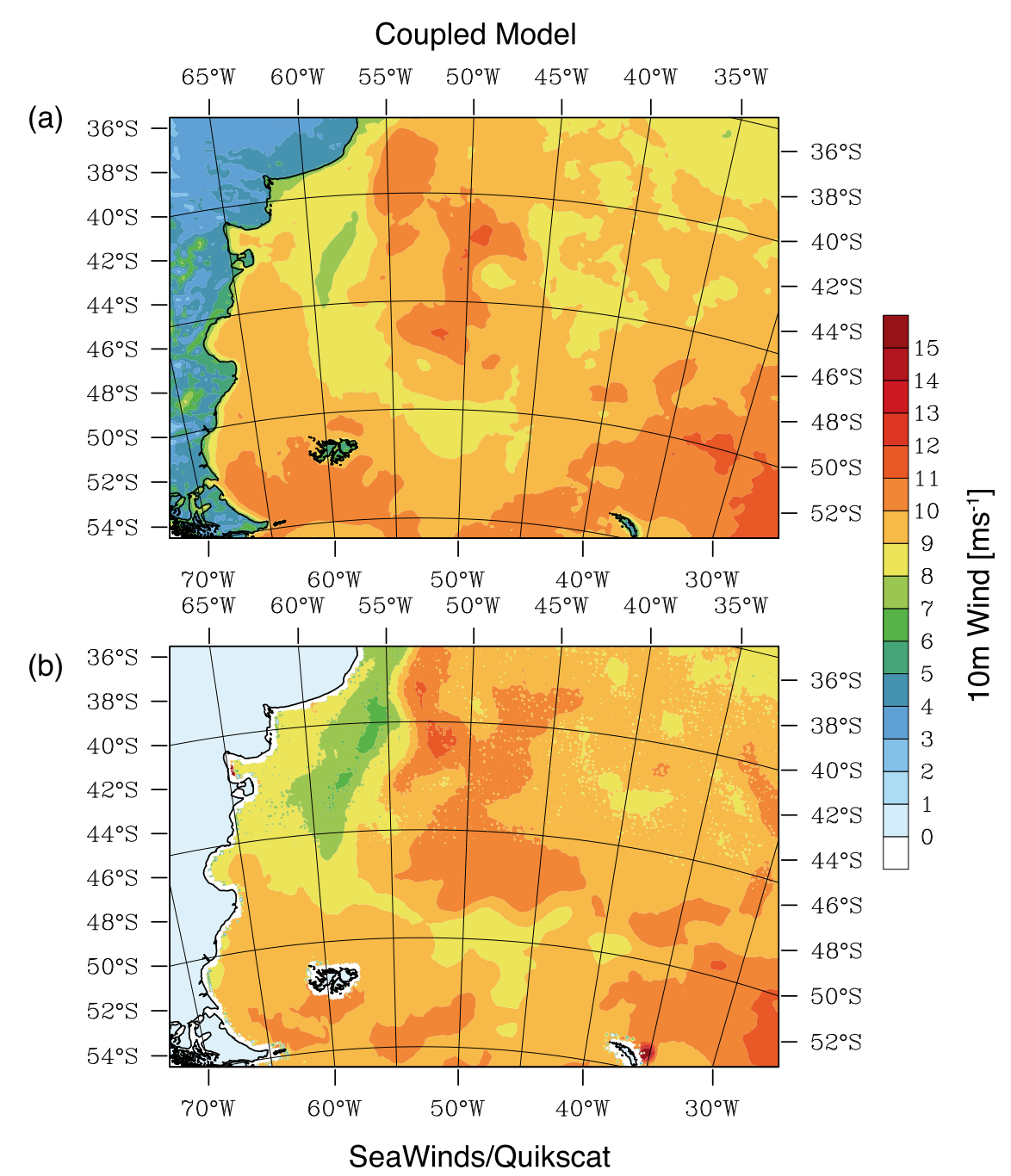

FIG. 3. Seasonal-mean 10-m wind comparison: (a) coupled model and (b) SeaWinds on QuikSCAT.

from ERA-Interim, with the coupled model providing dynamical downscaling to simulate the local conditions at higher resolution. Thus, the coupled model has a realistic representation of the background atmospheric state. However, it shows increased small-scale variability because of the higher spatial resolution and the inclusion of an underlying highly resolved SST field. Of particular concern for this study is the accurate representation of the wind field because of its potential importance in determining the dominant mechanism responsible for the atmospheric response to underlying SST anomalies. Figure 3 shows that the austral winter mean wind speed at $10 \mathrm{~m}$ from the coupled model compares favorably with the observed 10-m winds from SeaWinds on QuikSCAT. However, the probability density function reveals that the coupled model (red curve) underrepresents stronger winds $\left(23-30 \mathrm{~m} \mathrm{~s}^{-1}\right)$ when compared with QuikSCAT winds (black curve; Fig. 4). However, we do not believe this to affect the accurate determination of the mechanism responsible for the eddy-induced changes to the atmosphere. This is because it is the low wind speed range, that is, $\sim(0-15) \mathrm{m} \mathrm{s}^{-1}$, where different mechanisms can be of importance.

To evaluate the magnitude of the atmospheric response to the underlying SST pattern, we compare mean composites of atmospheric variables above the identified eddies for both models and observations. Sensitivity studies were conducted to ensure the robustness of the results. These included first comparing only eddies detected in the model that were of the same size as those detected in satellite observations $(>50 \mathrm{~km})$, more specifically comparing composites and anomalies of eddies of different size classes. Second, the model eddy field is 


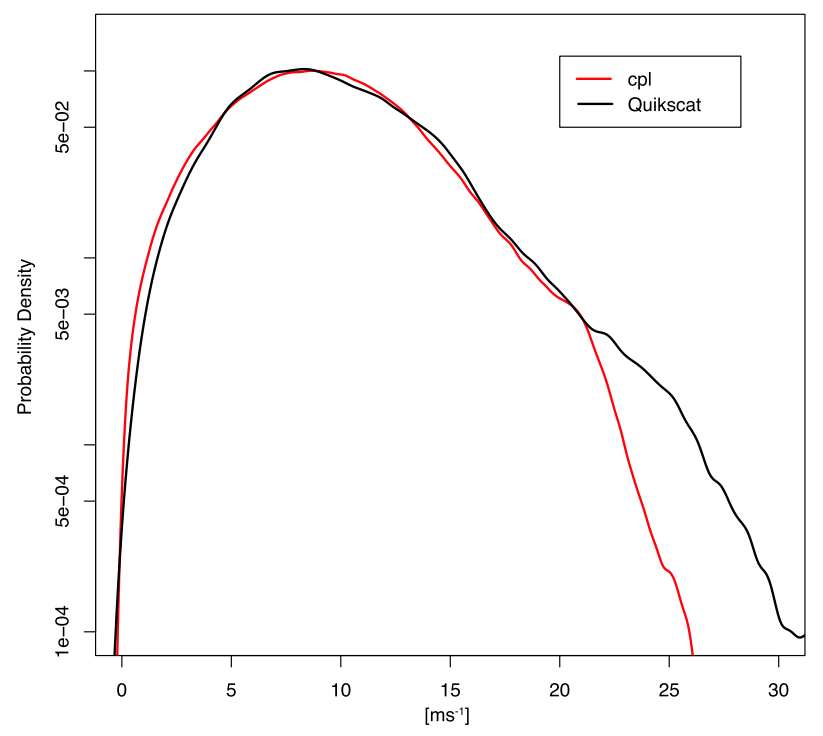

FIG. 4. Probability density function of 10-m wind: coupled model (red curve) and SeaWinds on QuikSCAT (black curve).

sampled weekly rather than 6 hourly, which ensures that the number of eddies for the statistics between the model and observations are similar. Third, only a sample of eddies from different areas of the domain is used to test the dependence on the background environment, and finally, composites and anomalies calculated from OW- and VG-detected eddies are compared. In all cases the results were robust, with values for anomalies of wind stress and latent and sensible heat fluxes varying by no more than $10 \%$ of the results given below. Precipitation and cloud fraction anomalies were more sensitive, varying by $16 \%$ and $35 \%$, respectively (see supplementary material).

The reason for this robustness, as will be shown, is that the atmospheric response depends on the magnitude of the temperature anomaly and also the background wind speed. The different sensitivity studies above can be thought of as a subset sampling of a total set of eddies and atmospheric states. As long as these subsets are not skewed, as evidenced in Figs. 1c-h, then they represent a subset that samples the total set evenly, that is, with an even distribution in location (background wind speed) and temperature anomaly, and it stands to reason that the anomaly calculation will be robust.

Here we present results from Okubo-Weiss applied to satellite observations ( $\sim 3000$ eddy instances) and vector geometry applied to the model $(\sim 78000$ eddy instances), where the VG method is chosen for the model because of its superior signal-to-noise ratio for computing spatial derivatives for the momentum balance. However, for eddy composites, coupling strengths, and momentum balance terms computed from OW-detected eddies, see supplementary material.

\section{1) WIND STRESS ANOMALY}

The model reproduces quite well the observed spatial structure of the wind stress response inferred from microwave radar wind data from SeaWinds on QuikSCAT (Fig. 5). The good agreement includes not only the details of the wind speed pattern above the eddies, but also the background wind gradient, which primarily reflects the north-south gradient of the dominant westerlies in this region (Figs. 5a,d). To quantify the change in wind stress as a function of the magnitude of the underlying SST anomaly, we compute binned averages of the wind stress anomaly, defined as the difference between the mean of the eddy area (a circle two radii around the center of the eddy) and the background (a ring of three radii around this circle; Fig. $5 \mathrm{~g}$ ). The linear relationship, first discovered by Chelton et al. (2001) and which we refer to hereafter as coupling strength, gives approximately a value of $\left(\Delta \tau \approx \pm 0.02 \mathrm{~N} \mathrm{~m}^{2}\right)$ or $7 \%-10 \%$ change per degree of temperature. This is in good agreement with the satellite observations for the region and also agrees with estimates reported in the literature for observational studies for the Southern Ocean (O'Neill et al. 2003), Agulhas return current (O'Neill et al. 2005), Gulf Stream region (Chelton and Xie 2010), and model studies (Spall 2007).

The dipole structure of the wind stress divergence is correlated with the downwind SST gradient and shows that the flow is accelerated from cold to warm (divergence) and decelerated from warm to cold (convergence) and is spatially localized directly over the SST frontal regions (Figs. 5b,e). Furthermore, SST anomalies associated with eddies induce changes in the wind stress curl (Figs. 5c,f).

It is of note that there are two mechanisms that can modify the wind stress curl over eddies: 1) the anomaly associated only with changes in wind over the eddy and 2 ) the curl caused by taking into account the ocean surface current in the wind stress calculation. The latter effect is generally thought to be much larger and typically gives rise to a monopole pattern for wind stress curl over eddies (Chelton 2013). For this study, we wish to quantify the atmospheric response purely to the change arising from the temperature anomaly, and therefore, in the model, the ocean surface velocities are not taken into account for the calculation of $\tau$. While QuikSCATmeasured wind stress is based on relative wind and therefore includes the ocean surface current, the wind stress curl pattern derived from satellite observations is dipole, showing that the dominant pattern is derived 
(a)
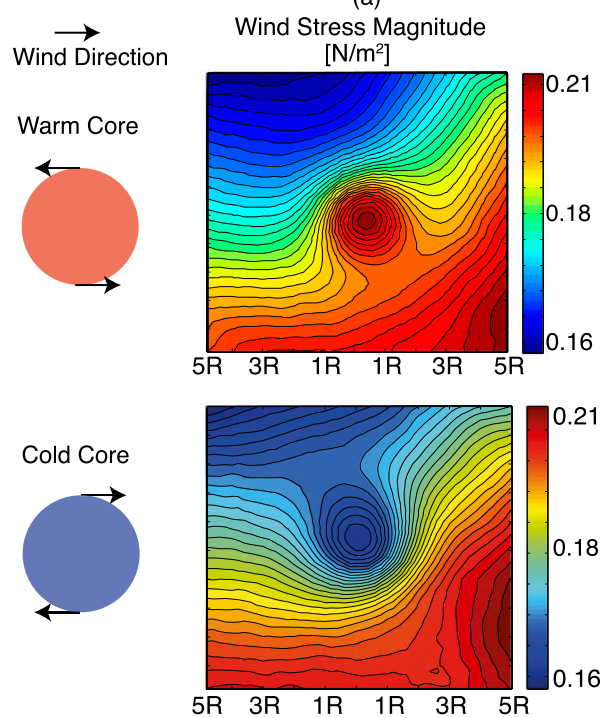

(d)

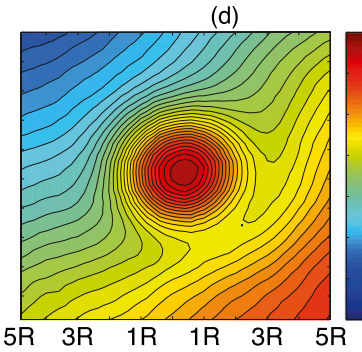

0.18
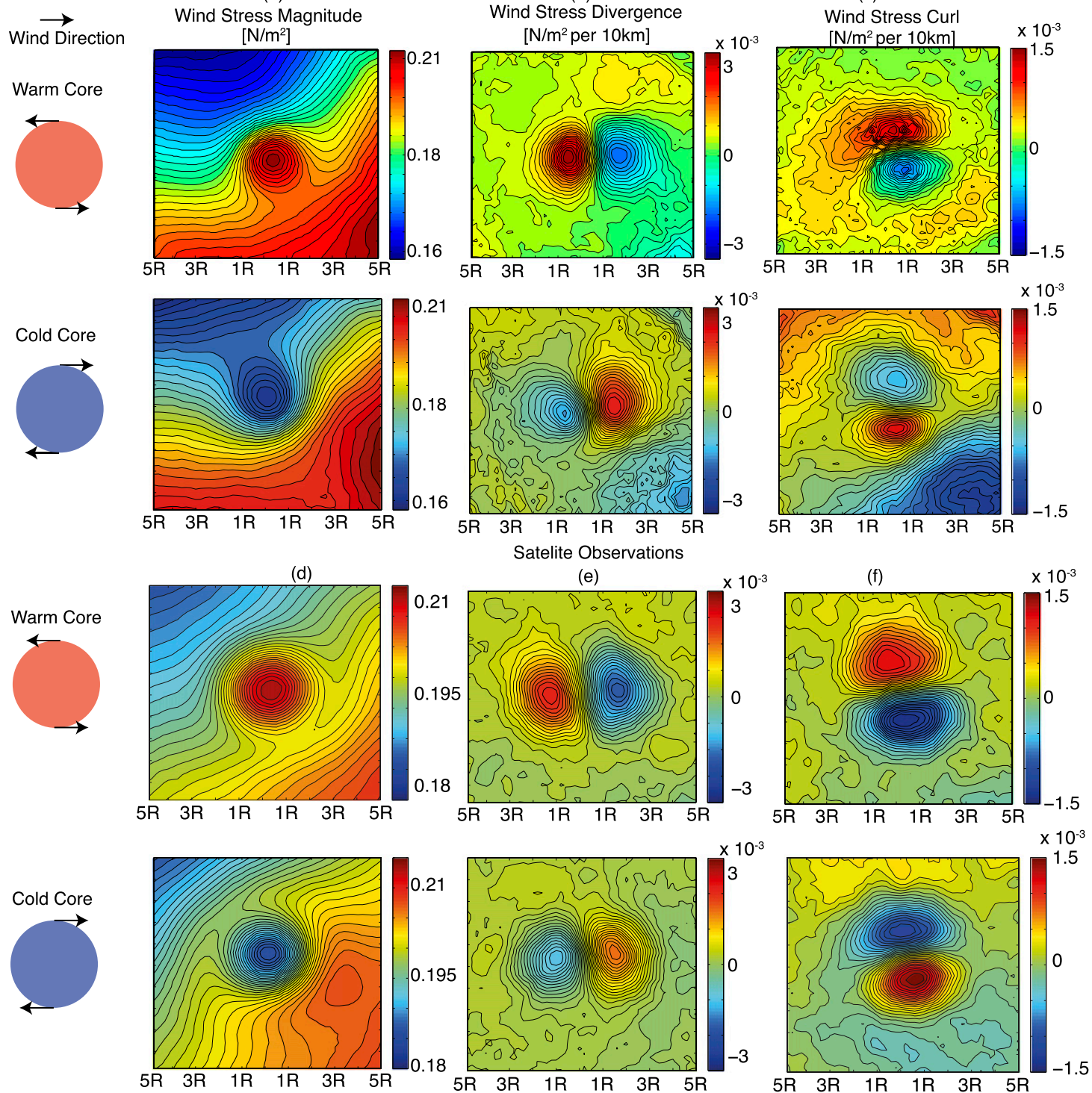

(g) Binned Wind Stress Change per degree of SST Anomaly

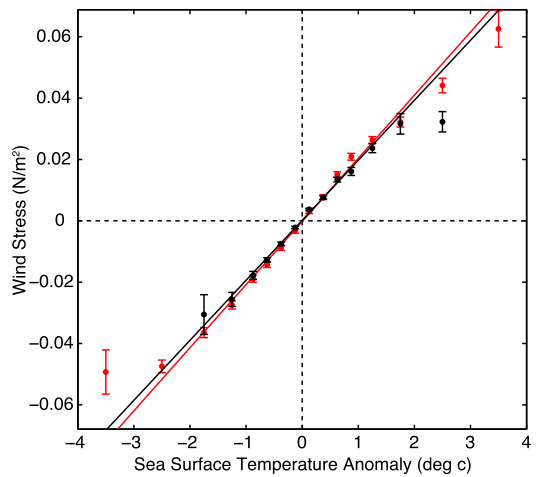

FIG. 5. Wind stress anomalies above eddies. COSMO-ROMS model results: (a) wind stress, (b) divergence, and (c) curl above anticyclonic (warm core) and cyclonic (cold core) eddies. Satellite observations from SeaWinds on QuikSCAT: (d) wind stress anomaly, (e) divergence, and (f) curl anomalies. (g) Binned averages of satellite (black) and model (red) wind stress per degree of temperature anomaly. 
from the changes in wind due to the SST anomaly and not the ocean surface current. We therefore argue that a direct comparison between the model and satellitebased observations is still valid.

\section{2) HeAt FluXes, ClOUd COVER, AND RAIN}

Associated with the modulation of the SST due to eddies are a $\pm 10 \mathrm{~W} \mathrm{~m}^{-2} \approx \pm 66 \%$ change in the sensible and $\pm 21 \mathrm{~W} \mathrm{~m}^{-2} \approx 28 \%$ change in the latent heat flux per degree of temperature anomaly (Figs. 6a-d). These anomalies feed into the hydrological cycle by increasing/decreasing evaporation $\left( \pm 0.7 \mathrm{~mm} \mathrm{day}^{-1} \approx\right.$ $\pm 28 \%$ ), which drives increases/decreases in convective precipitation over cold and warm core eddies (Fig. 7a), and whose signal is visible in the total precipitation (Fig. 7b).

While the spatial pattern for total precipitation is reasonable compared with satellite observations (Figs. 7b,c), the model underrepresents the coupling strength $\left(0.16 \mathrm{~mm} \mathrm{day}{ }^{-1}{ }^{\circ} \mathrm{C}^{-1} \approx \pm 5.9 \%{ }^{\circ} \mathrm{C}^{-1}\right)$ compared with satellite observations $\left( \pm 0.25 \mathrm{~mm} \mathrm{day}{ }^{-1}{ }^{\circ} \mathrm{C}^{-1} \approx 8.5 \%{ }^{\circ} \mathrm{C}^{-1}\right)$ for this region (Fig. 7d). However, it is in fairly good agreement with coupling strengths derived from satellite observations for the whole Southern Ocean $\left( \pm 0.17 \mathrm{~mm} \mathrm{day}^{-1}{ }^{\circ} \mathrm{C}^{-1}\right)$ over eddies (Frenger et al. 2013).

The model performs relatively poorly for cloud fraction changes because of eddies (Figs. 8a,b). However, some change is clearly visible in the mean spatial pattern (Fig. 8a) and where the more sensitive coupling strength calculation estimates a change in cloud fraction of $\approx \pm 2.2 \%{ }^{\circ} \mathrm{C}^{-1}$ in the model compared with $\pm 3.6 \%{ }^{\circ} \mathrm{C}^{-1}$ from satellite observations (Fig. 8c). These changes are in agreement with satellite observations for the whole Southern Ocean for cloud fraction $\left( \pm 2 \%{ }^{\circ} \mathrm{C}^{-1}\right.$; Frenger et al. 2013).

\section{3) Conclusion of evaluation}

The overall excellent agreement of the coupled model with satellite-derived observations of the same region for both the spatial structure and magnitude of the atmospheric response to underlying SST anomalies shows that the coupled model provides a realistic platform with which to study the underlying mechanisms.

\section{Mechanisms}

\section{a. Wind stress anomalies}

The spatial pattern of the wind stress divergence, that is, the dipole structure, already provides semiquantitative evidence for the dominance of the mixing term (Figs. 5b,e; Frenger et al. 2013). But in order to determine this in a more quantitative manner, we identify the dominant terms in the zonal momentum balance Eq. (1). Here we recast the problem in terms of

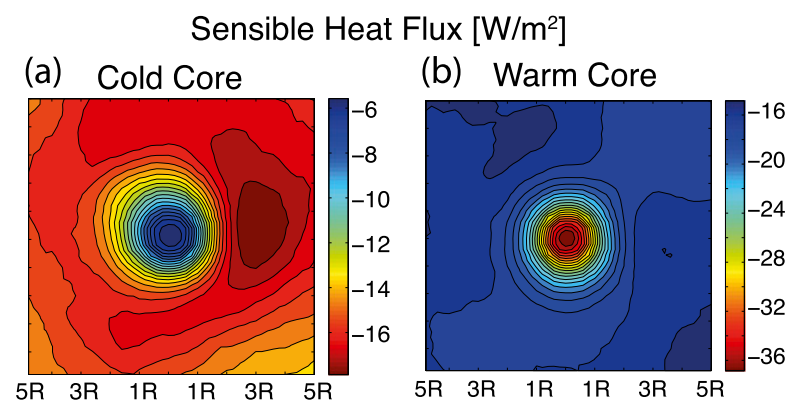

(c)
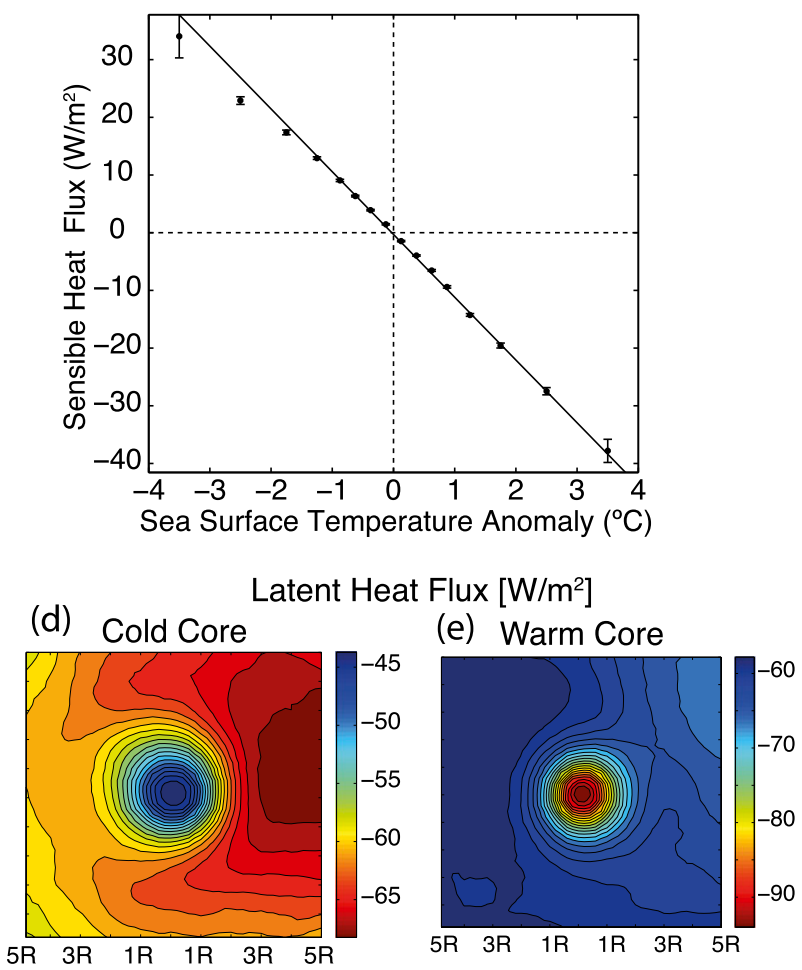

(f)

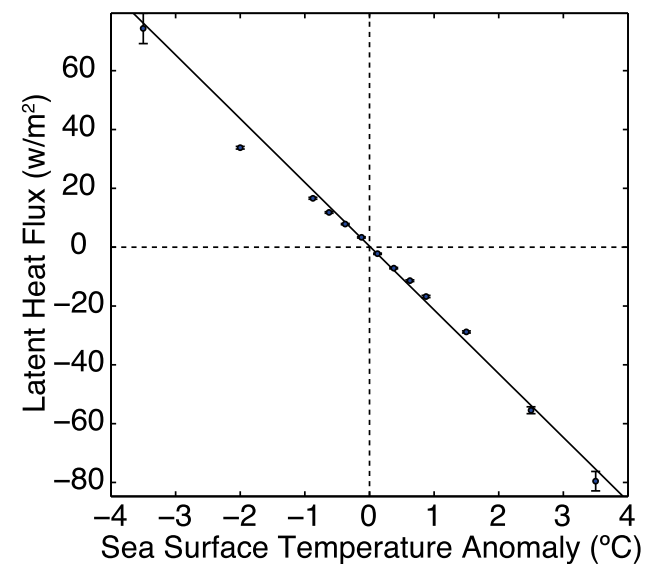

FIG. 6. Composite analysis of sensible and latent heat flux over (a),(d) cold-core and (b),(e) warm-core eddies. Coupling strength as a function to SST anomaly for (c) sensible and (f) latent heat flux. The sign convention is such that negative is heat loss from the ocean to the atmosphere. 


\section{Convective Precipitation [mm/day] (Coupled model)}

(a)
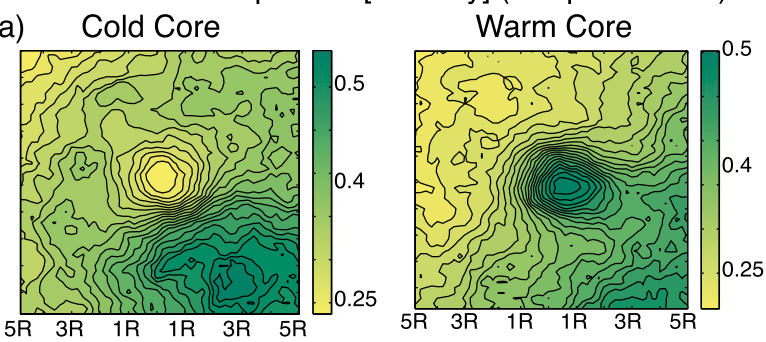

(b) Total Precipitation [mm/day] (Coupled Model)
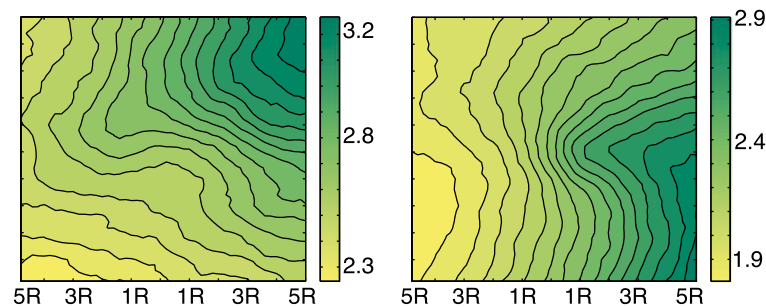

(c) Total Precipitation [mm/day] (Satellite Observations)
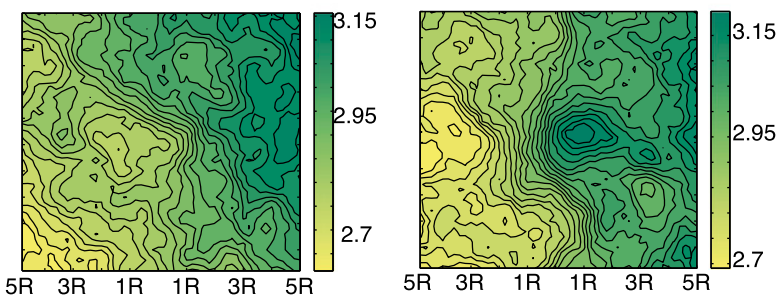

(d)

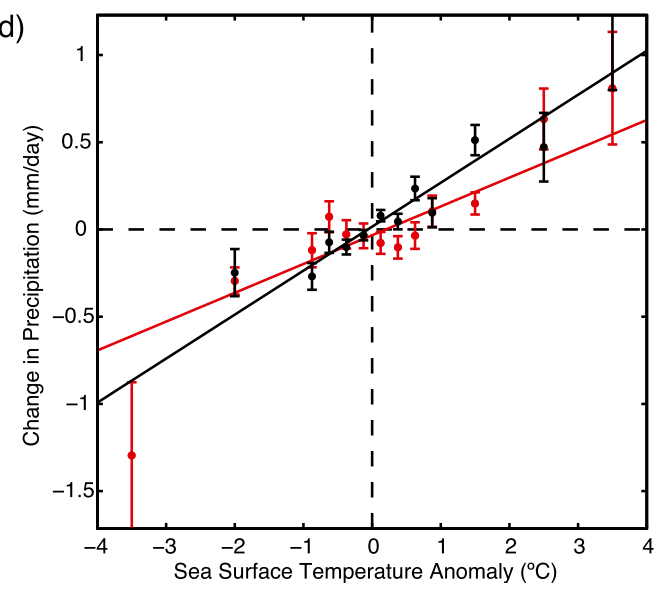

FIG. 7. Composite analysis over cold- and warm-core eddies for (a) convective precipitation for coupled model and total precipitation for (b) coupled model and (c) satellite observations. (d) Coupling strength for total precipitation as a function of SST anomaly for satellite observations (black curve) compared to the coupled model (red curve).

the anomaly, where for each eddy instance the background field is subtracted. For consistency, the background is again defined as the area mean of a ring of three radii around the defined eddy area (a circle two radii around the center of the eddy). Figure 9 shows vertical cross sections of the mean composite of the

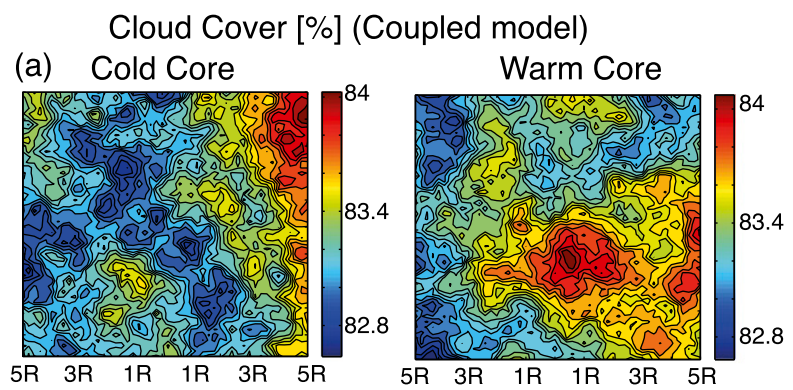

(b) Cloud Cover [\%] (Satellite Observations)
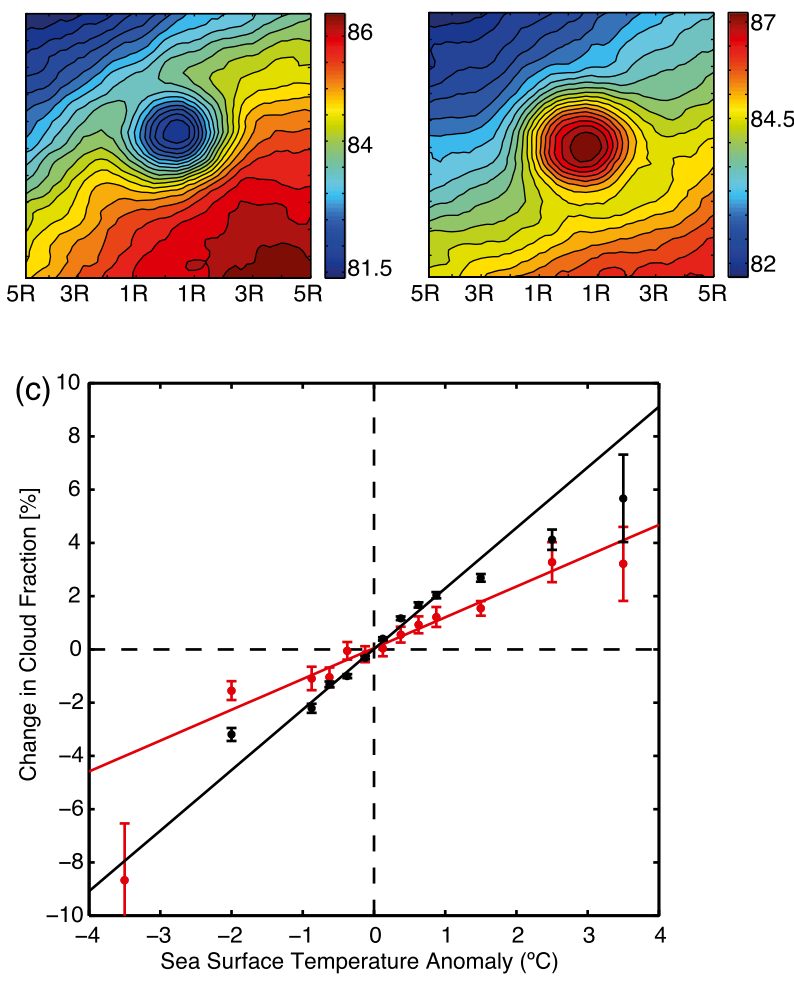

FIG. 8. Composite analysis over cold- and warm-core eddies for cloud fraction for (a) coupled model and (b) satellite observations. (c) Coupling strength as a function of SST anomaly for satellite observations (black curve) compared to the coupled model (red curve).

anomalous terms in the momentum balance along a chord through the center of the anomaly from upwind to downwind of the front. Positive terms represent an acceleration of the flow downwind that, in the mean, is approximately aligned zonally.

For reference, Fig. 9a shows the average temperature anomaly for warm- and cold-core eddies and defines the SST frontal regions from $-2 R$ to $+2 R$ with the maximum at the eddy center. The atmospheric response above warm and cold SST anomalies is relatively symmetric (Figs. 9b-e). On the upwind front, $-2 R$, cold (warm) to warm (cold), a positive (negative) pressure anomaly develops that is balanced by a negative 
Warm Core

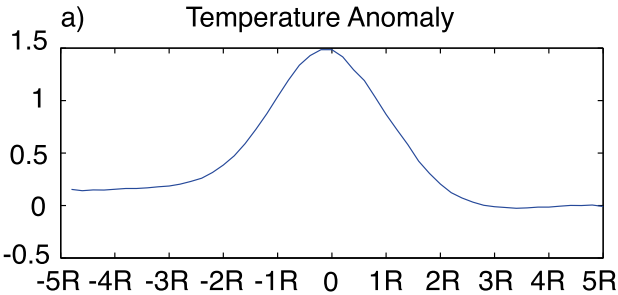

b)

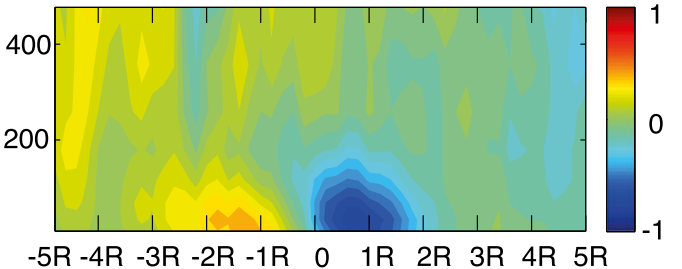

c) Pressure Gradient

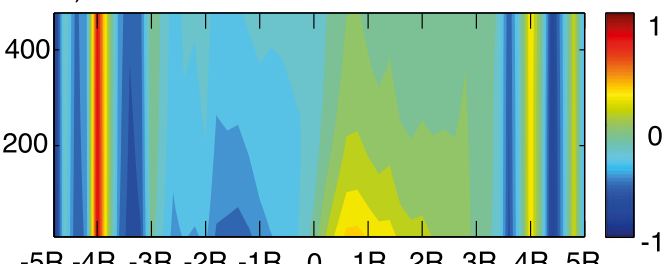

d) $\quad$ Coriolis $\times 10^{-4}$

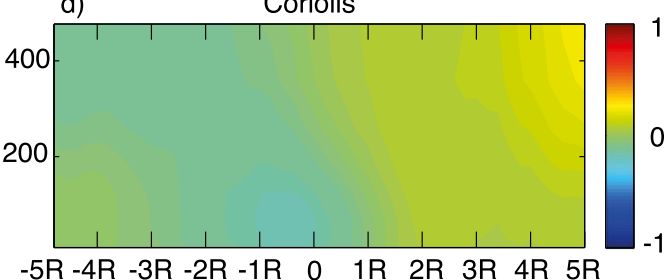

Mixing $\times 10^{-4}$

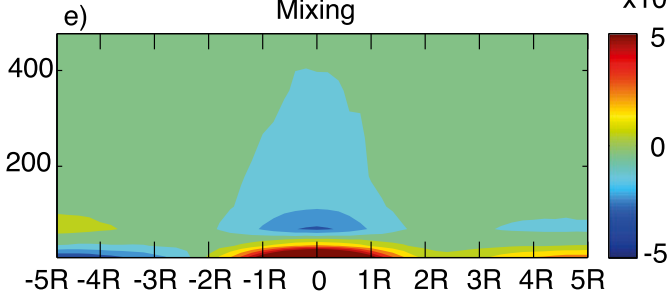

Cold Core

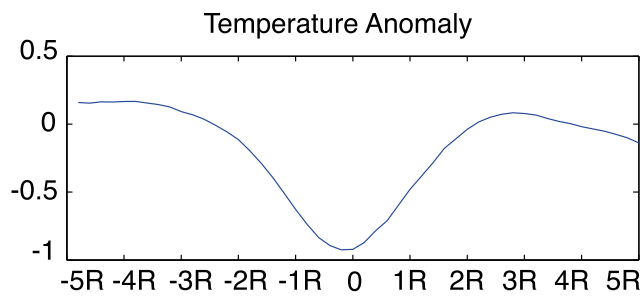

Advection

$\mathrm{x} 10^{-4}$

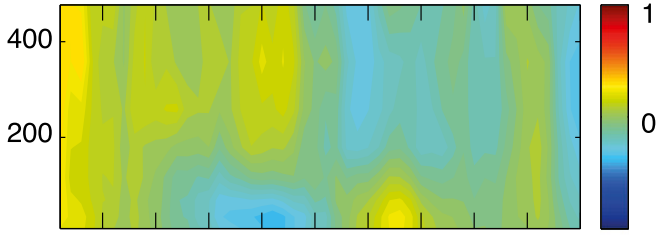

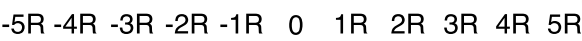

Pressure Gradient

$\mathrm{x} 10^{-4}$
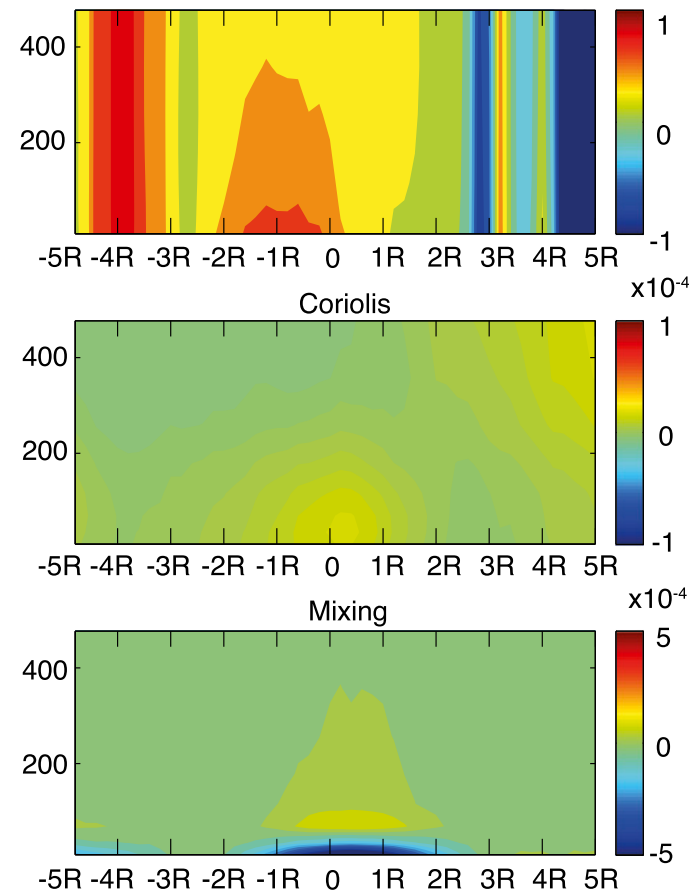

FIG. 9. Vertical cross sections of the mean composite of the terms in the momentum balance equation along a chord through the center of the SST anomaly from upwind to downwind for (left) cold core and (right) warm core.

(positive) advection term, farther downwind as the second front is crossed, then the pressure and advection anomaly terms change sign but remain balanced. The Coriolis term by comparison plays almost no role, as by definition in the rotated coordinate system $f v$ is approximately zero at the surface. Higher in the boundary layer the Coriolis term decelerates/accelerates the flow consistent with the "Coriolis torque" described by Spall (2007). However, the main driving term is the mixing term, which accelerates/decelerates the surface wind and decelerates/accelerates the wind above and whose maxima/minima are aligned with the maxima/minima of the wind stress anomaly (Figs. 5a,b). The reversal in sign of the mixing term is consistent with the vertical mixing mechanism reported in other studies (Skyllingstad et al. 2007; O'Neill et al. 2010; Kilpatrick et al. 2014).

These results represent the mean over all eddy size classes, lifetimes, and temperature anomalies, and one could argue that the mean does not represent the general case for different-size eddies; for example, as indicated via the scale analysis in the introduction, the mechanism could change from smaller- to larger-scale 
a)

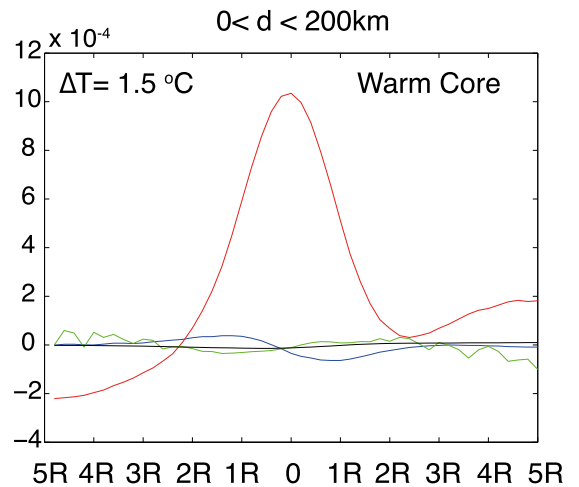

b)

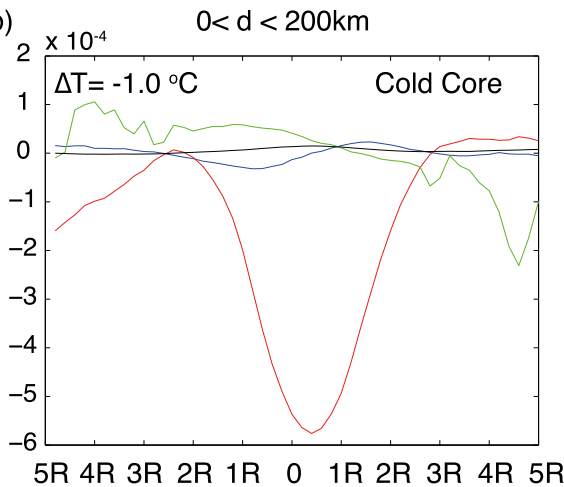

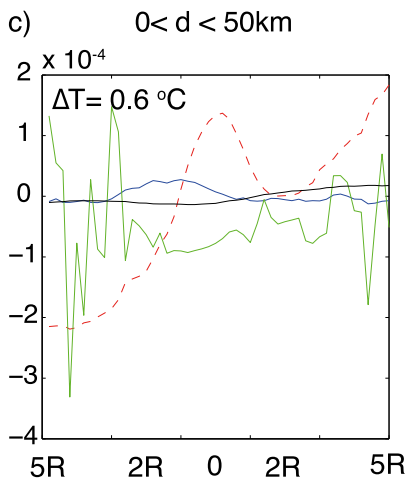

d) $50 \mathrm{~km}<\mathrm{d}<100 \mathrm{~km}$

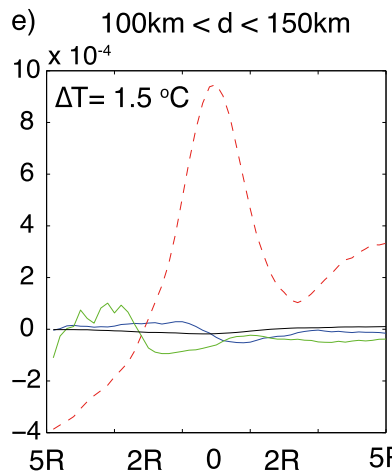

f) $150 \mathrm{~km}<\mathrm{d}<200 \mathrm{~km}$
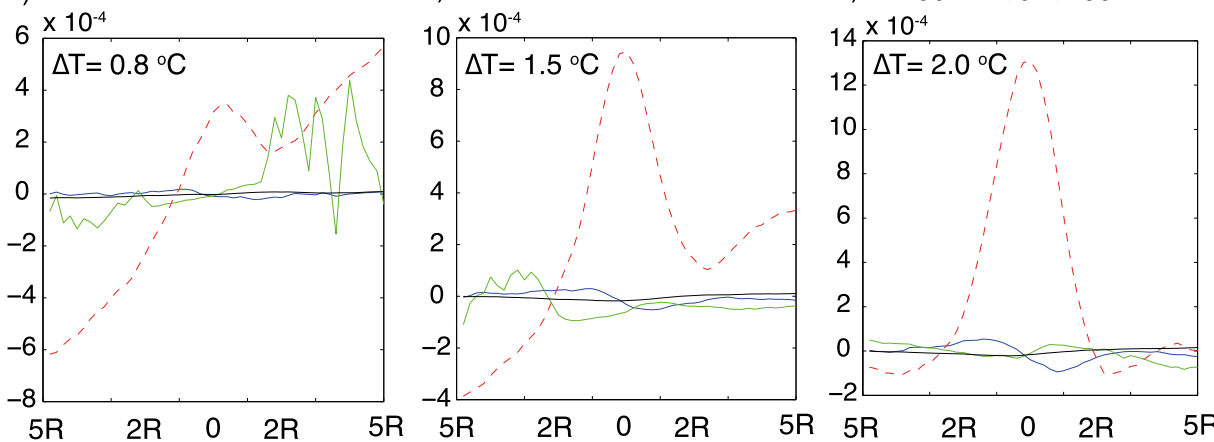

FIG. 10. Lowest model level ( $\sim 10 \mathrm{~m}) U$-momentum balance of advection (blue), horizontal pressure gradient (green), Coriolis (black), and mixing (red) terms, along a chord through the center of the SST anomaly from upwind to downwind. Mean calculated of binned size classes of eddies of diameter $d$. (a) All eddies warm core $0<d<200 \mathrm{~km}$, (b) all eddies cold core $0<d<200 \mathrm{~km}$, (c) $0<d<50 \mathrm{~km}$, (d) $50<d<100 \mathrm{~km}$, (e) $100<d<150 \mathrm{~km}$, and (f) $150<d<200 \mathrm{~km}$.

eddies. To investigate this, we now compare different size classes. For comparison, Fig. 10 shows the terms in the $U$-momentum budget of the same central chord as the vertical cross sections (Fig. 9) at the lowest model level $(10 \mathrm{~m})$ for warm (Fig. 10a)- and cold (Fig. 10b)-core eddies for the mean over all eddies, the average temperature anomaly $(+1.5$ for warm and -1 for cold is indicated). Figures 10c-f show the same lowest model level chord for different binned size classes of $<50,50-100$, 100-150, and 150-200 km, respectively. Despite the differing magnitude of the temperature anomaly associated with each size class, the mechanism responsible remains the same. For diameters $<50 \mathrm{~km}$, defined by $-2 R$ to $+2 R$, the advection and pressure terms, while still balanced, do not adjust on short enough spatial scales to see the second front at $+2 R$. For the advection and pressure terms, the effect of the second front starts to become more apparent as the diameter of the eddy increases $50-100 \mathrm{~km}$ and becomes fully resolved for eddies $>150 \mathrm{~km}$. However, it is clear that in all cases, it is the unbalanced mixing term that is driving the changes and that it rapidly changes for each front.

The main driver for changes in turbulent diffusion of momentum $\left\langle u^{\prime} w^{\prime}\right\rangle=K_{m}(z) d u / d z$ is predominantly changes in the diffusion coefficient. Figure 11 shows the mean vertical diffusion coefficient of momentum, plotted as the total field for illustration, centered over the eddy (black dashed curve) compared to locations upwind at $-4 R$ (red) and downwind $+4 R$ (blue), of warm (Fig. 11a) and cold (Fig. 11b) SST anomalies. Indeed, the magnitude of the change of the vertical diffusion coefficient over eddies, $\Delta K_{m} \approx \pm 10 \%{ }^{\circ} \mathrm{C}^{-1}$, is consistent with the magnitude change in wind stress $\Delta \tau \approx \pm(7 \%-10 \%){ }^{\circ} \mathrm{C}^{-1}$ (Fig. 12a) and while not shown, the horizontal $2 \mathrm{D}$ slice is also consistent with the spatial pattern of the air-sea heat flux changes (Fig. 6). It is thus the rapid change in the vertical mixing coefficient that increases over warm SST anomalies or reduces over cold SST anomalies that drive the change in the surface wind. The stability effect on the drag coefficient is of secondary importance, $\Delta C_{d} \approx \pm 5 \times 10^{-5}{ }^{\circ} \mathrm{C}^{-1} \approx \pm 3.6^{\circ} \mathrm{C}^{-1}$ (Fig. 12b), meaning that changes in the wind stress are driven primarily by changes in the $10-\mathrm{m}$ wind, where $\tau=\rho_{0} C_{d}\left|U_{10}\right| U_{10}$.

The boundary layer height also responds to underlying SST anomalies with an increase/decrease over warm- and cold-core eddies, respectively $(\Delta h \approx$ $\pm 80 \mathrm{~m}^{\circ} \mathrm{C}^{-1} \approx \pm 7.9^{\circ} \mathrm{C}^{-1} ;$ Figs. 13a-c). The interpretation of Samelson and Skyllingstad (2006), where the wind 

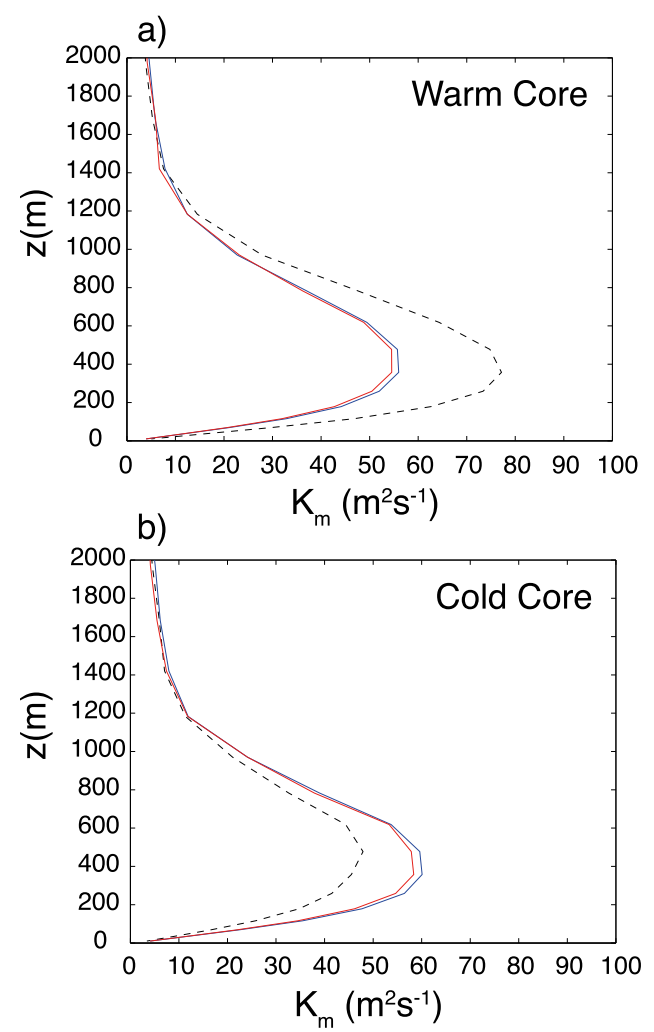

FIG. 11. Vertical diffusion coefficient of momentum, upwind (red) located at $-4 R$, centered over maximum temperature anomaly (black dashed) and downwind $+4 R$ (blue) for (a) warm-core and (b) cold-core composites.

response can be explained from a one-dimensional balance $\tau \sim-G h$, requires that there is little to no advection and the Coriolis term is ignored, which does not hold here. While there is a linear relationship between wind stress and boundary layer height change (Fig. 13d), there is a clear deviation from the linear relationship for larger temperature anomalies, and it therefore does not explain the linear response of the wind (Fig. $5 \mathrm{~g}$ ).

\section{b. Changes in mixing driving precipitation and cloud anomalies}

The spatial pattern and strength of the evaporation, precipitation, and cloud cover signals due to eddies are also consistent with the mixing mechanism being dominant. In general, how the anomalous moisture flux is related to changes in cloud cover and precipitation depends strongly on the synoptic-scale flow. Under low wind conditions, a warm SST anomaly might trigger convection and lead to an associated release of latent heat and precipitation. This would result in an alignment of the precipitation, low-level wind convergence, and the SST anomalies. On the other hand, under high wind conditions, surface moisture would be quickly mixed (a)

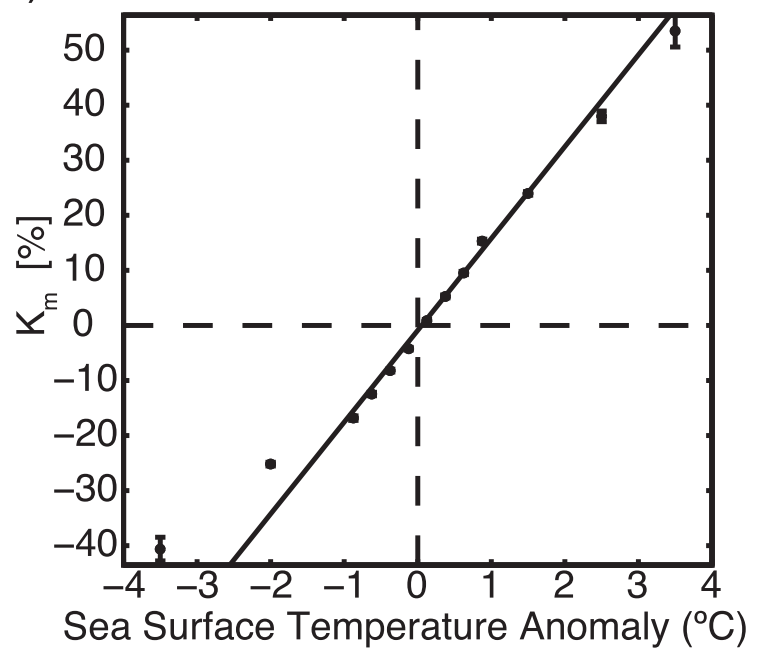

(b)

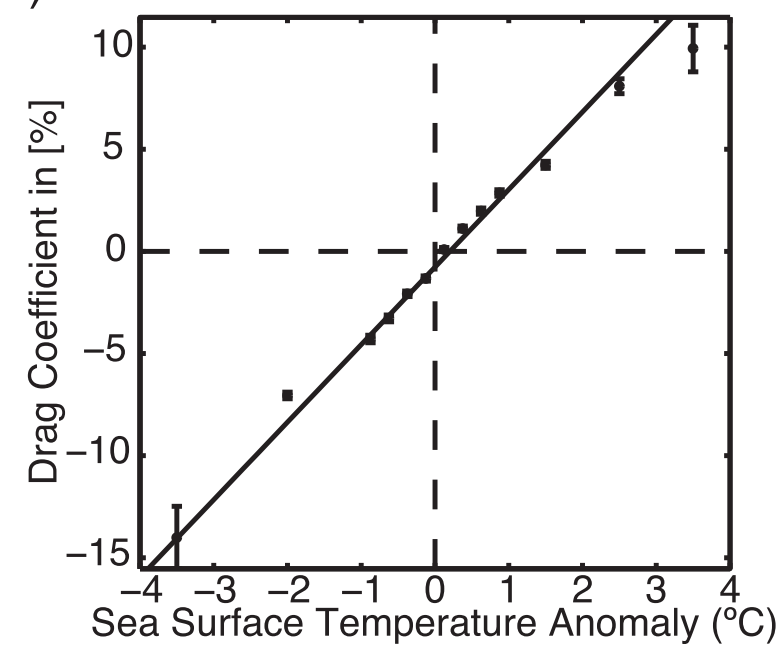

FIG. 12. Percentage change per degree of temperature anomaly:

(a) vertical diffusion of momentum and (b) drag coefficient.

with the surrounding boundary layer air, which would result in far less organized convection and thus fewer cumulus clouds. In this case, one would expect a slight increase of precipitation downwind of the SST anomaly because of the increased moisture content and increased instability in the boundary layer.

For reference, Fig. 14a shows the magnitude and the different length scale of adjustment of the mean sea level pressure and vertical diffusion coefficient along a chord through the center of the anomaly from upwind to downwind of the front. Black dotted lines represent the maximum wind convergence/divergence in Figs. 5a and 5b.

Figures $14 \mathrm{~b}$ and $14 \mathrm{c}$ show the precipitation (green curve) and cloud cover (blue curve) along the same chord. In the coupled model, the precipitation maximum (minimum) for warm and cold SST anomalies coincide 


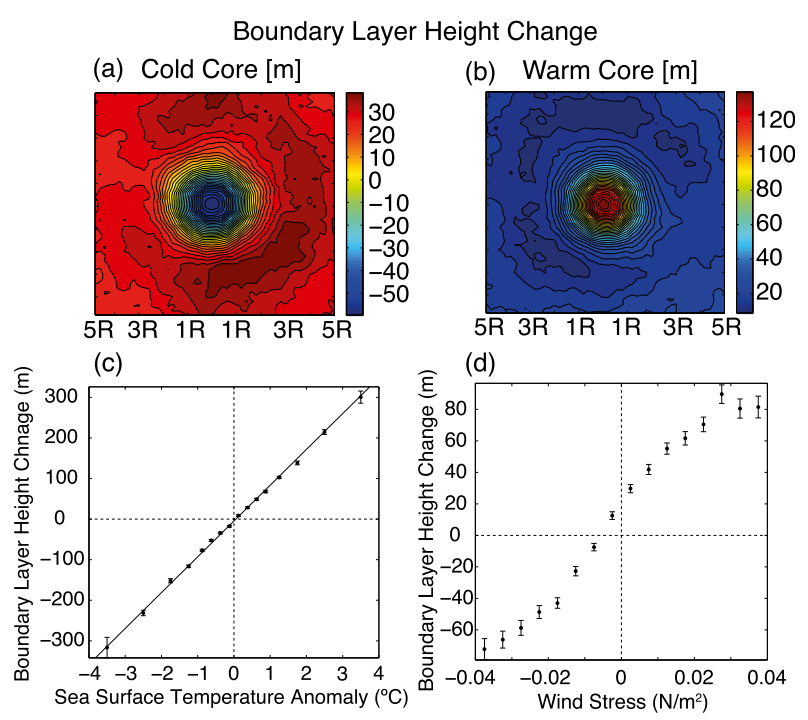

FIG. 13. Boundary layer height change (underlying eddy minus no eddy simulations): (a) cyclonic (cold core), (b) anticyclonic (warm core). (c) Boundary layer height change per degree of temperature anomaly, and (d) boundary layer height change vs change in wind stress.

with the maximum (minimum) of the change in the vertical diffusion of momentum coefficient and not with the low-level convergence marked by the black dotted line. The positions of the maximum (minimum) are also not correlated with the SST maximum (minimum) and are farther downwind, with this being far more pronounced in the case of the warm SST anomaly. The increase/decrease in low-level cloud fraction (blue curve) is also strongly correlated with the change in the vertical mixing coefficient and is not centered over the low-level convergence (Fig. 14b).

\section{c. Coupling strength}

Some studies have found a seasonal signal in the coupling strength (O'Neill et al. 2005; Putrasahan et al. 2013), but the reasons are not known. One study suggested that this is simply a consequence of seasonal variations in the large-scale wind speed Spall (2007). Further, one might expect a dependence on the largescale atmospheric stability, for instance, a damped response of the atmosphere under stable conditions.

To investigate this, we bin the coupling strength (atmospheric quantity change per degree of SST anomaly) above eddies based on the background wind speed and for different background stability, here taken as the temperature difference between $10 \mathrm{~m}$ and the sea surface (Fig. 15).

In general, for all atmospheric quantities, there is an increase in the coupling strength with increasing background wind speeds with the exception being the planetary boundary layer height that shows no clear dependence (Fig. 15b). On the whole, the dependence of the coupling strength on the cross-front wind speed is not quadratic, and polynomial curve fits produce only a small improvement in $r$-squared values over simple linear fits.

However, the effect of stability is not the same for all quantities. Wind-related variables show largest coupling strength, varying by an order of magnitude at $\alpha_{c} \approx 0.005-0.05 \mathrm{~N} \mathrm{~m}^{-2}{ }^{\circ} \mathrm{C}^{-1}$ at neutral stability (black curve) and lowest coupling strength for unstable conditions $\alpha_{c} \approx 0.002-0.02 \mathrm{~N} \mathrm{~m}^{-2}{ }^{\circ} \mathrm{C}^{-1}$ (green and blue curves, Fig. 15a).

As expected, sensible and latent heat fluxes have greater coupling strengths for unstable conditions (i.e., larger air-sea temperature differences), ranging from $\alpha_{c} \approx$ $5-25 \mathrm{~W} \mathrm{~m}^{-2}{ }^{\circ} \mathrm{C}^{-1}$ to $\alpha_{c} \approx 10-40 \mathrm{~W} \mathrm{~m}^{-2}{ }^{\circ} \mathrm{C}^{-1}$ (green and blue curves, Figs. 15c,d) for sensible and latent, respectively, compared with more stable condition coupling strengths $\alpha_{c} \approx 3-15 \mathrm{~W} \mathrm{~m}^{-2}{ }^{\circ} \mathrm{C}^{-1}$ and $\alpha_{c} \approx 5-25 \mathrm{~W} \mathrm{~m}^{-2}{ }^{\circ} \mathrm{C}^{-1}$ (black and red curves, Figs. $15 \mathrm{c}, \mathrm{d})$.

On the other hand, evaporation is linked directly to the latent heat flux and therefore shows strongest coupling strength for unstable conditions. The precipitation response is more complicated, where unstable conditions (green and blue curve) do not show a strong difference over neutral stability (black curve) and indeed the background wind strength plays a much more important role in determining the coupling strength (Figs. $15 \mathrm{e}, \mathrm{f})$. That the wind strength is more important is consistent with the mixing mechanism being dominant.

\section{Summary and conclusions}

This study analyses the atmospheric response to SST anomalies associated with mesoscale eddies and builds on the current literature, which considered mostly single, larger-scale, temperature fronts. Mesoscale eddies are far more numerous and offer a different class of problem in that they are predominantly circular, smaller in scale, and offer two temperature fronts.

The coupled model utilized in this study shows both semiquantitative (in terms of the spatial structure of the atmospheric response) and quantitative agreement with satellite-derived observations of the same region. This gives us the confidence to argue that the coupling strength presented here represents realistic values and may be used to represent the atmospheric response to general, midlatitude mesoscale eddies in the Southern Ocean.

First, these results suggest that the mechanism responsible for the observed changes in surface winds is due to an increase/a decrease of the vertical mixing and confirms claims that the dipole pattern of the wind divergence may be interpreted as an indication for the dominance of 
Cold Core (Coupled Model)

(a)

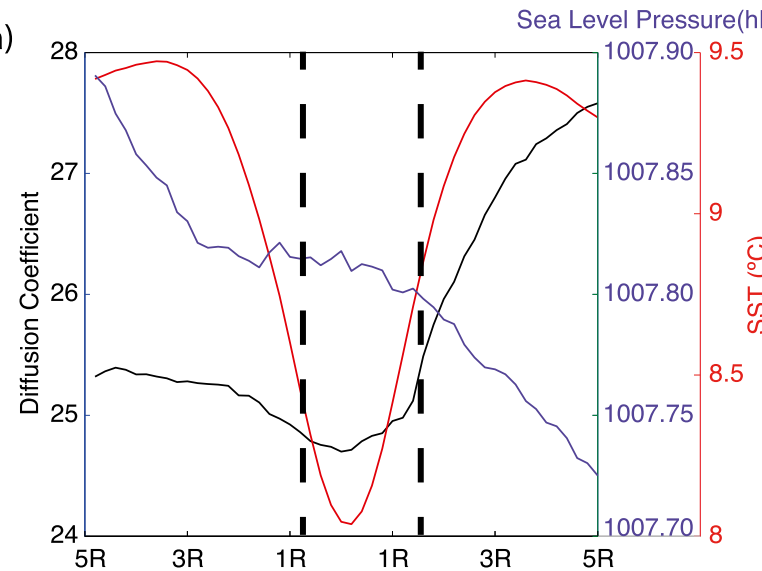

(b)

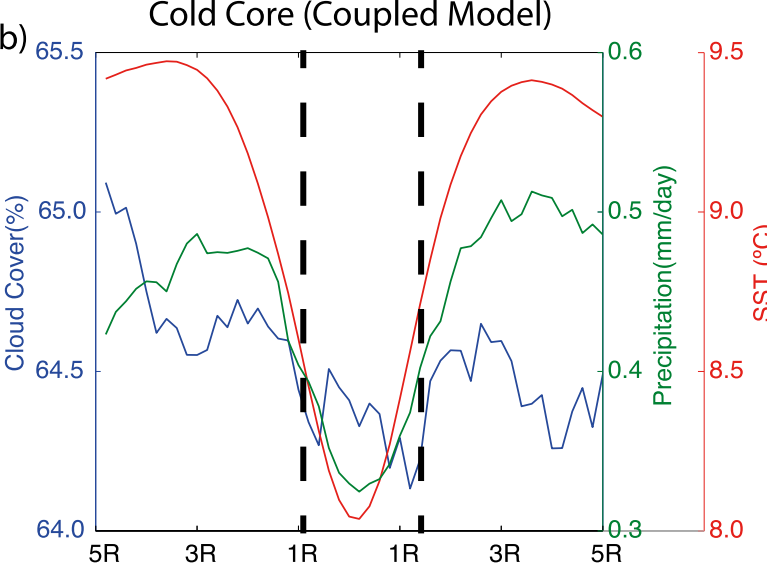

(c) Cold Core (Satellite Observations)

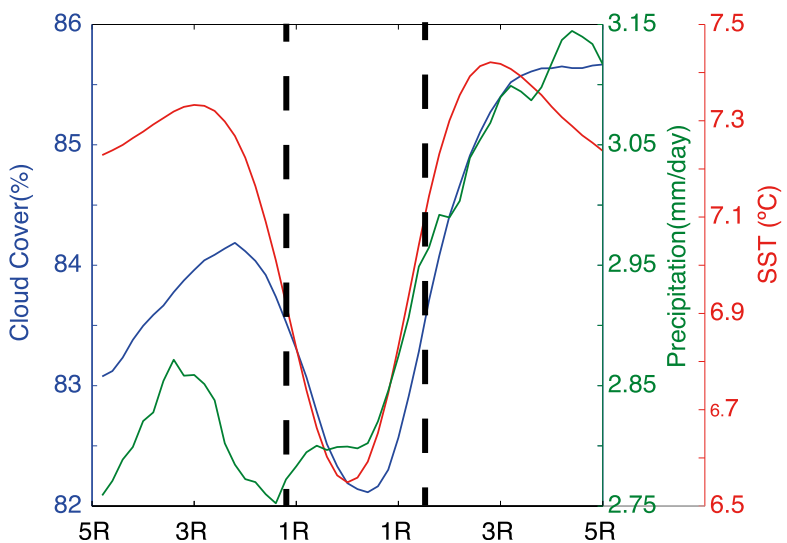

Warm Core (Coupled Model)

Sea Level Pressure $(\mathrm{hPa})$

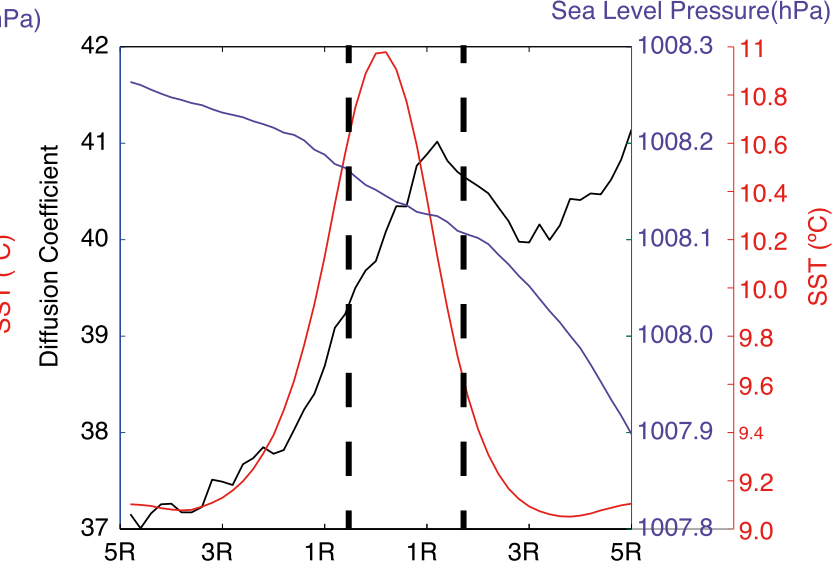

Warm Core (Coupled Model)
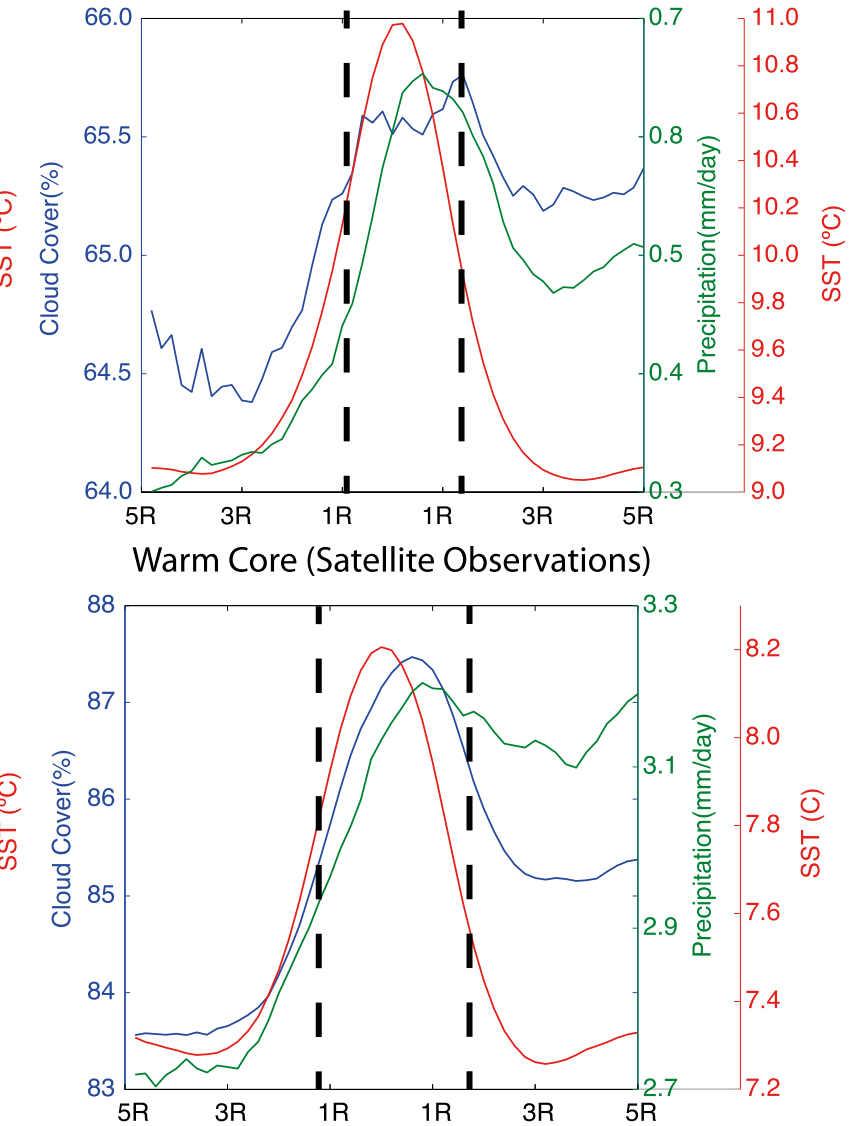

FIG. 14. Magnitude of atmospheric quantities along a chord through the center of the SST anomaly (red curve) from upwind to downwind of the front of (a) mean sea level pressure (purple curve) and vertical diffusion coefficient (black curve), (b) precipitation (green curve) and cloud cover (blue curve), and (c) satellite observations of precipitation (green curve) and cloud cover (blue curve).

this mechanism. Because of the strength and consistency of the background westerlies in the Southern Ocean, the dominance of the vertical mixing of momentum is not an unexpected result. Indeed, this study shows that horizontal pressure anomalies are small at these scales.
The wind stress change coincides with a linear change in boundary layer height in agreement with Samelson and Skyllingstad (2006); however, it deviates significantly for larger temperature anomalies and thus does not explain the observed wind stress change. In addition, 


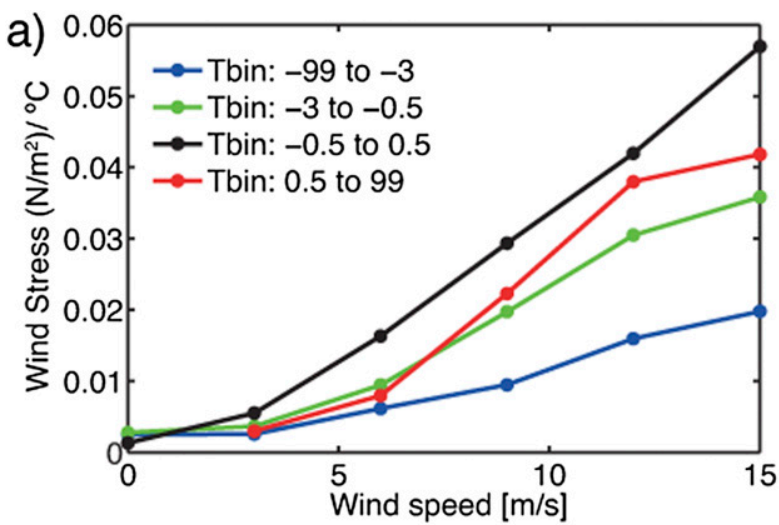

b)
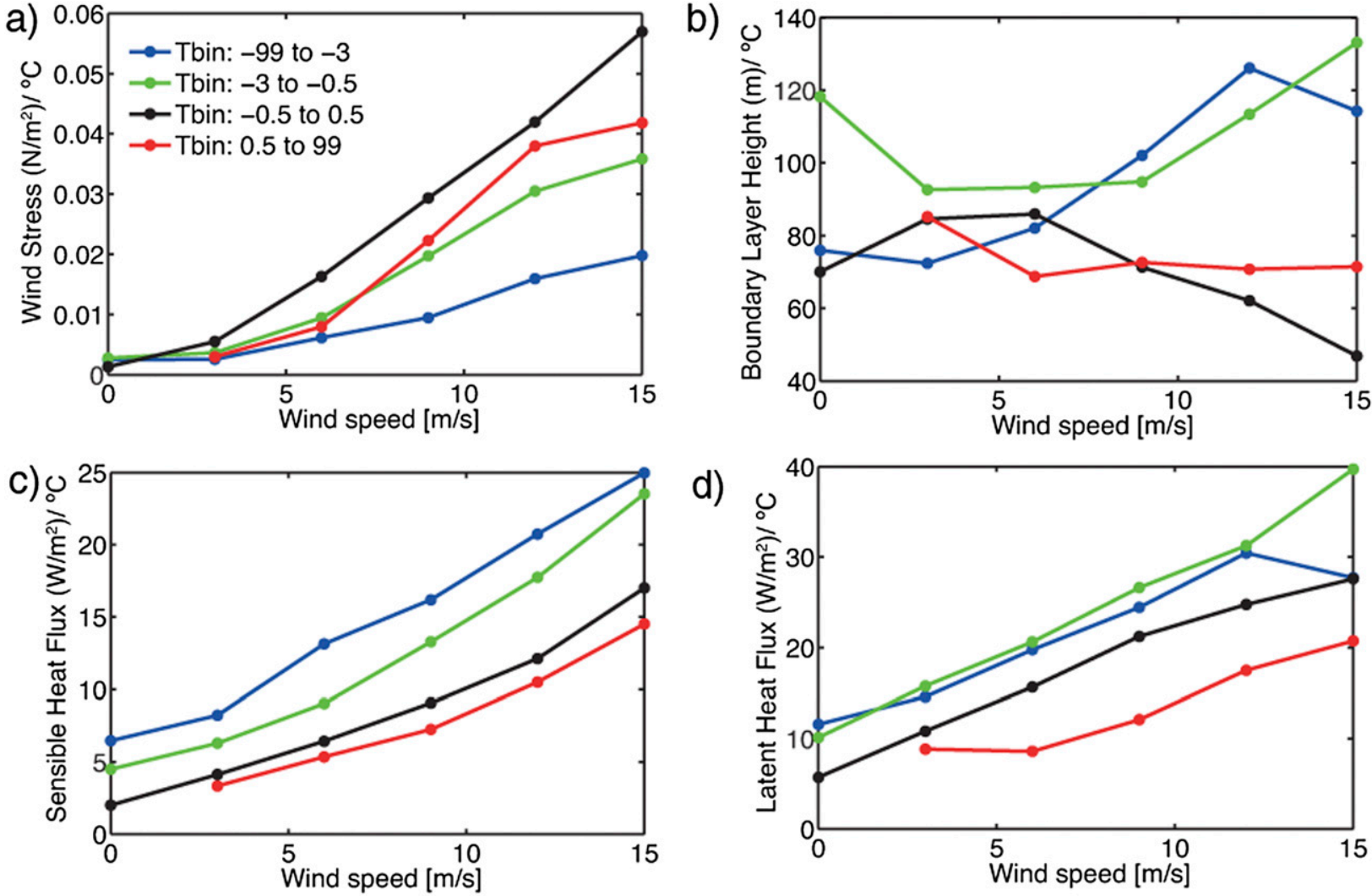

d)
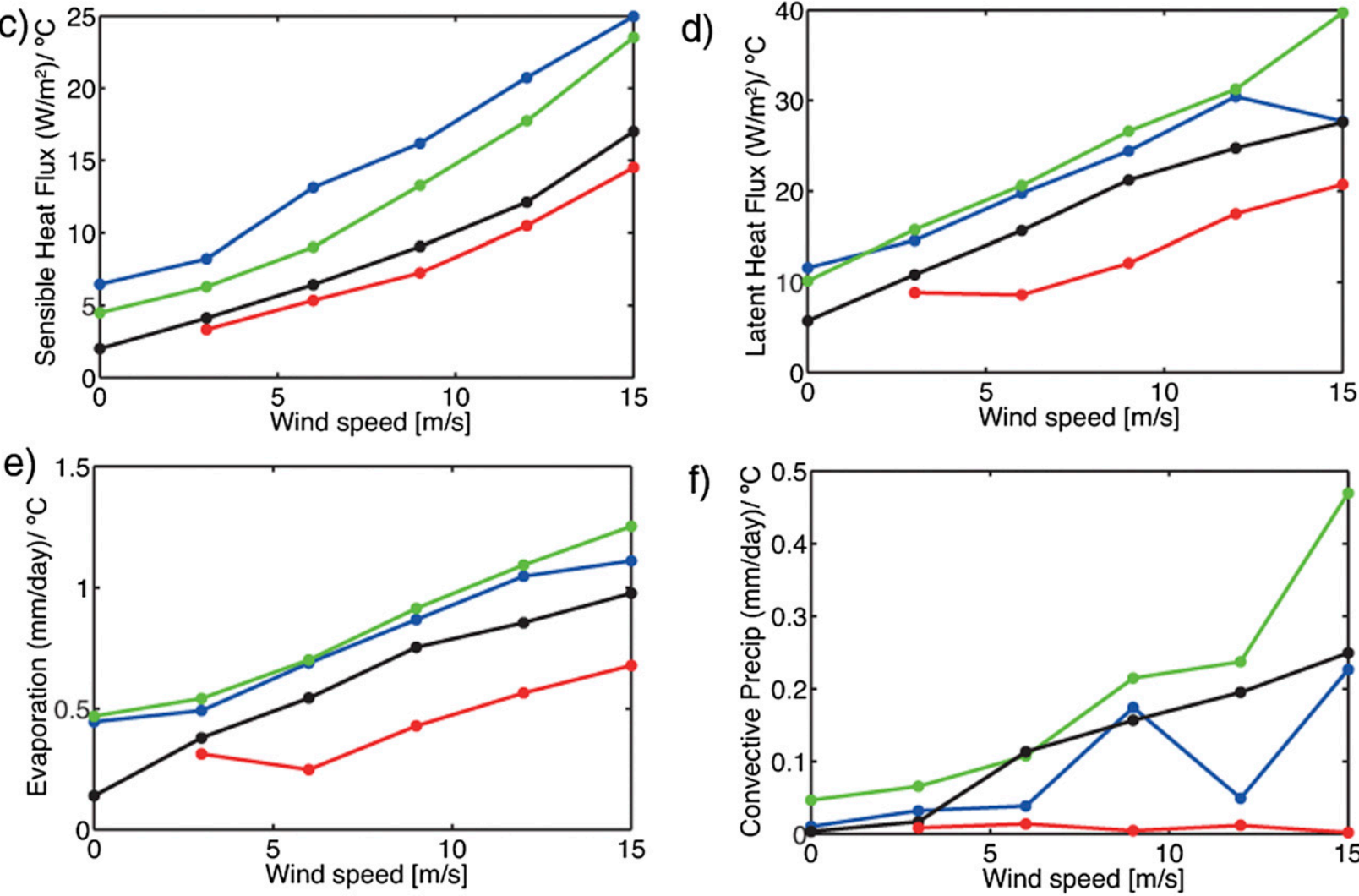

f)

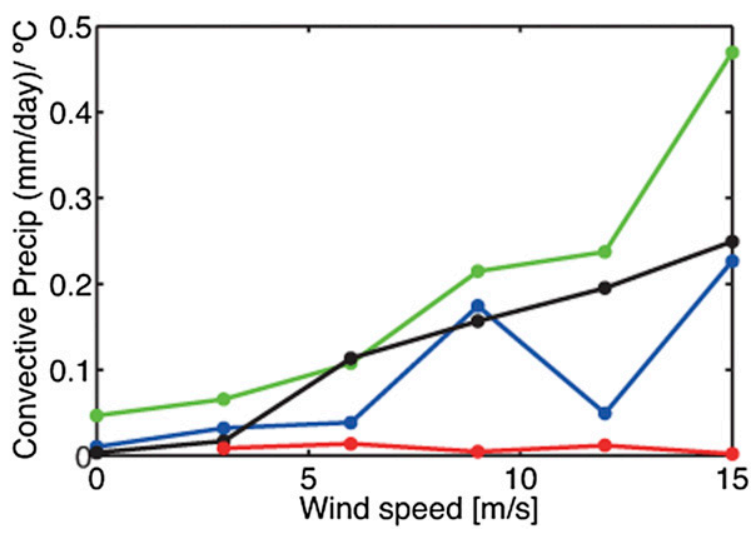

FIG. 15. Coupling strength of atmospheric quantities binned based on stability (10-m SST) and background wind speed: (a) wind stress, (b) planetary boundary layer height, (c) sensible heat flux, (d) latent heat flux, (e) evaporation, and (f) precipitation.

wind stress coupling strength shows dependence on both stability and background wind, but boundary layer height does not, further reinforcing that the relationship proposed by Samelson and Skyllingstad (2006) does not hold for the mesoscale eddies considered here.

Our model and observation-based results provide additional support to the growing evidence that oceanatmosphere interactions at the mesoscale form an important component of the Earth system. However, many open questions still remain that are beyond the scope of this paper.
First, it is not clear how and even if the ocean responds to the induced changes in the wind forcing. While studies of the ocean response to changes in mesoscale forcing are few, it is already apparent that the feedback due to small-scale variations is important and is not restricted to local changes but can have profound effects on the ocean circulation, for example, strengthening or weakening basin-scale gyres (Milliff et al. 1999; Hogg et al. 2009) or dampening the growth rate of tropical instability waves (Seo et al. 2007).

Second, the induced changes in low-level cloud have considerable implications for the radiation budget 
through increased/decrease reflected solar and longwave radiation. Indeed, (Bony et al. 2006) showed that shortwave feedback is the largest source of intermodel spread in climate sensitivity. It is not feasible to run such a high-resolution fully coupled model for climatological time scales; therefore, we must parameterize these effects in coarser-resolution models.

To this end, the understanding of the mechanisms responsible is essential; moreover, the magnitude of the adjustment of atmospheric quantities is needed, for example, the change per degree of SST anomaly. With the multiple mechanisms that must be considered and that the dominant one is based on the local conditions, such as background wind speed, boundary layer height, and stability, here we take the approach to quantify the response in terms of the mechanism and coupling strength that is dominant in the mean state. Here we provide coupling strengths for atmospheric variables, and because of the good agreement with observations, these results can potentially provide a basis for the functional form of the coupling strength in a parameterization scheme in coarser-resolution models.

In this regard, this study provides several different levels of complexity, where, in the simple case, a single change per degree of temperature can be used for each atmospheric variable based on the mean stability and background wind speed or, in the more complex case, a different functional from of the coupling strength dependence on wind speed can be assigned for diagnosed local stable, unstable, and neutral conditions.

Acknowledgments. This work has been supported by ETH Research Grant CH2-01 11-1, "Modeling the Water Cycle in a Changing Climate: A Multiscale Interaction Challenge." We acknowledge the technical support of the Center for Climate Systems Modeling, Stephan Pfahl, and Anne Roches and are grateful to the two anonymous reviewers for their comments, which helped to improve the manuscript.

\section{REFERENCES}

Bony, S., and Coauthors, 2006: How well do we understand and evaluate climate change feedback processes? J. Climate, 19, 3445-3482, doi:10.1175/JCLI3819.1.

Bryan, F. O., R. Tomas, J. M. Dennis, D. B. Chelton, N. G. Loeb, and J. L. McClean, 2010: Frontal scale air-sea interaction in high-resolution coupled climate models. J. Climate, 23, 6277 6291, doi:10.1175/2010JCLI3665.1.

Carton, J., and G. Chepurin, 2000: A simple ocean data assimilation analysis of the global upper ocean 1950-95. Part I: Methodology. J. Phys. Oceanogr., 30, 294-309, doi:10.1175/ 1520-0485(2000)030<0294:ASODAA $>2.0 . C O ; 2$.

Chelton, D. B., 2013: Ocean-atmosphere coupling: Mesoscale eddy effects. Nat. Geosci., 6, 594-595, doi:10.1038/ngeo1906.

_ and S. Xie, 2010: Coupled ocean-atmosphere interaction at oceanic mesoscales. Oceanography, 23, 52-69, doi:10.5670/ oceanog.2010.05
- and Coauthors, 2001: Observations of coupling between surface wind stress and sea surface temperature in the eastern tropical Pacific. J. Climate, 14, 1479-1498, doi:10.1175/ 1520-0442(2001)014<1479:OOCBSW > 2.0.CO;2.

—, M. G. Schlax, M. H. Freilich, and R. F. Milliff, 2004: Satellite measurements reveal persistent small-scale features in ocean winds. Science, 303, 978-983, doi:10.1126/science.1091901.

Dee, D. P., and Coauthors, 2011: The ERA-Interim reanalysis: Configuration and performance of the data assimilation system. Quart. J. Roy. Meteor. Soc., 137, 553-597, doi:10.1002/qj.828.

de Szoeke, S. P., and C. S. Bretherton, 2004: Quasi-Lagrangian large eddy simulations of cross-equatorial flow in the east Pacific atmospheric boundary layer. J. Atmos. Sci., 61, 1837-1858, doi:10.1175/1520-0469(2004)061<1837:QLESOC>2.0.CO;2.

Fairall, C. W., E. F. Bradley, D. P. Rogers, J. B. Edson, and G. S. Young, 1996: Bulk parameterization of air-sea fluxes for Tropical Ocean-Global Atmosphere Coupled-Ocean Atmosphere Response Experiment difference relative analysis. J. Geophys. Res., 101, 3747-3764, doi:10.1029/95JC03205.

Frenger, I., N. Gruber, R. Knutti, and M. Münnich, 2013: Imprint of Southern Ocean eddies on winds, clouds and rainfall. Nat. Geosci., 6, 608-612, doi:10.1038/ngeo1863.

Hayes, S., M. McPhaden, and J. Wallace, 1989: The influence of seasurface temperature on surface wind in the eastern equatorial Pacific: Weekly to monthly variability. J. Climate, 2, 1500-1506, doi:10.1175/1520-0442(1989)002<1500:TIOSST>2.0.CO;2.

Hogg, A. M. C., W. K. Dewar, P. Berloff, S. Kravtsov, and D. K. Hutchinson, 2009: The effects of mesoscale ocean-atmosphere coupling on the large-scale ocean circulation. J. Climate, 22, 4066-4082, doi:10.1175/2009JCLI2629.1.

Kilpatrick, T., N. Schneider, and B. Qiu, 2014: Boundary layer convergence induced by strong winds across a midlatitude SST front. J. Climate, 27, 1698-1718, doi:10.1175/ JCLI-D-13-00101.1.

Louis, J., 1979: A parametric model of vertical eddy fluxes in the atmosphere. Bound.-Layer Meteor., 17, 187-202, doi:10.1007/ BF00117978.

Mahrt, L., D. Vickers, and E. Moore, 2004: Flow adjustments across sea-surface temperature changes. Bound.-Layer Meteor., 111, 553-564, doi:10.1023/B:BOUN.0000016600.63382.5f.

Mellor, G. L., and T. Yamada, 1974: A hierarchy of turbulence closure models for planetary boundary layers. J. Atmos. Sci., 31, 1791-1806, doi:10.1175/1520-0469(1974)031<1791:AHOTCM>2.0.CO;2.

Milliff, R., W. G. Large, J. Morzel, G. Danabasoglu, and T. M. Chin, 1999: Ocean general circulation model sensitivity to forcing from scatterometer winds. J. Geophys. Res., 104, 11 337-11 358, doi:10.1029/1998JC90004.

Minobe, S., A. Kuwano-Yoshida, N. Komori, S.-P. Xie, and R. J. Small, 2008: Influence of the Gulf Stream on the troposphere. Nature, 452, 206-209, doi:10.1038/nature06690.

Müller, E., 1981: Turbulent flux parameterization in a regional-scale model. Proc. ECMWF Workshop on Planetary Boundary Layer Parameterization, Reading, United Kingdom, ECMWF, 193-220.

Nencioli, F., C. Dong, T. Dickey, L. Washburn, and J. C. McWilliams, 2010: A vector geometry-based eddy detection algorithm and its application to a high-resolution numerical model product and high-frequency radar surface velocities in the Southern California bight. J. Atmos. Oceanic Technol., 27, 564-579, doi:10.1175/2009JTECHO725.1.

Okubo, A., 1970: Horizontal dispersion of floatable particles in the vicinity of velocity singularities such as convergences. Deep-Sea Res. Oceanogr. Abstr., 17, 445-454, doi:10.1016/ 0011-7471(70)90059-8. 
O'Neill, L. W., D. B. Chelton, and S. K. Esbensen, 2003: Observations of SST-induced perturbations of the wind stress field over the Southern Ocean on seasonal timescales. J. Climate, 16, 23402354, doi:10.1175/2780.1.

- $-\longrightarrow,-$, and F. J. Wentz, 2005: High-resolution satellite measurements of the atmospheric boundary layer response to SST variations along the Agulhas Return Current. J. Climate, 18, 2706-2723, doi:10.1175/JCLI3415.1.

—, S. K. Esbensen, N. Thum, R. M. Samelson, and D. B. Chelton, 2010: Dynamical analysis of the boundary layer and surface wind responses to mesoscale SST perturbations. J. Climate, 23, 559-581, doi:10.1175/2009JCLI2662.1.

Park, K.-A., P. Cornillon, and D. L. Codiga, 2006: Modification of surface winds near ocean fronts: Effects of Gulf Stream rings on scatterometer (QuikSCAT, NSCAT) wind observations. J. Geophys. Res., 111, C03021, doi:10.1029/2005JC003016.

Putrasahan, D. A., A. J. Miller, and H. Seo, 2013: Isolating mesoscale coupled ocean-atmosphere interactions in the Kuroshio Extension region. Dyn. Atmos. Oceans, 63, 60-78, doi:10.1016/ j.dynatmoce.2013.04.001.

Samelson, R., and E. Skyllingstad, 2006: On the coupling of wind stress and sea surface temperature. J. Climate, 19, 1557-1566, doi:10.1175/JCLI3682.1.

Seo, H., M. Jochum, R. Murtugudde, A. J. Miller, and J. O. Roads, 2007: Feedback of tropical instability-wave-induced atmospheric variability onto the ocean. J. Climate, 20, 5842-5855, doi:10.1175/JCLI4330.1.

Shchepetkin, A. F., and J. C. Mcwilliams, 2003: A method for computing horizontal pressure-gradient force in an oceanic model with a non-aligned vertical coordinate. J. Geophys. Res., 108, 3090, doi:10.1029/2001JC001047.

$\longrightarrow$, and - 2005: The regional oceanic modeling system (ROMS): A split-explicit, free-surface, topography-following-coordinate oceanic model. Ocean Modell., 9, 347-404, doi:10.1016/ j.ocemod.2004.08.002.

Shimada, T., and S. Minobe, 2011: Global analysis of the pressure adjustment mechanism over sea surface temperature fronts using AIRS/Aqua data. Geophys. Res. Lett., 38, L06704, doi:10.1029/ 2010GL046625.

Skyllingstad, E. D., D. Vickers, L. Mahrt, and R. Samelson, 2007: Effects of mesoscale sea-surface temperature fronts on the marine atmospheric boundary layer. Bound.-Layer Meteor. 123, 219-237, doi:10.1007/s10546-006-9127-8.

Small, R. J., S.-P. Xie, and Y. Wang, 2003: Numerical simulation of atmospheric response to Pacific tropical instability waves. J. Climate, 16, 3723-3741, doi:10.1175/1520-0442(2003)016<3723: NSOART $>2.0 . \mathrm{CO} ; 2$.

,,--- S. K. Ebensen, and D. Vickers, 2005: Numerical simulation of boundary layer structure and cross-equatorial flow in the eastern Pacific. J. Atmos. Sci., 62, 1812-1830, doi:10.1175/ JAS3433.1.

— , and Coauthors, 2008: Air-sea interaction over ocean fronts and eddies. Dyn. Atmos. Oceans, 45, 274-319, doi:10.1016/ j.dynatmoce.2008.01.001.

Song, Q., P. Cornillon, and T. Hara, 2006: Surface wind response to oceanic fronts. J. Geophys. Res., 111, C12006, doi:10.1029/ 2006JC003680.

Spall, M. A., 2007: Midlatitude wind stress-sea surface temperature coupling in the vicinity of oceanic fronts. J. Climate, 20, 3785-3801, doi:10.1175/JCLI4234.1.

Steppeler, J., G. Doms, U. Schättler, H. W. Bitzer, A. Gassmann, U. Damrath, and G. Gregoric, 2003: Meso-gamma scale forecasts using the nonhydrostatic model LM. Meteor. Atmos. Phys., 82, 75-96, doi:10.1007/s00703-001-0592-9.

Valcke, S., 2013: The OASIS3 coupler: A European climate modelling community software. Geosci. Model Dev., 6, $373-$ 388, doi:10.5194/gmd-6-373-2013.

Wallace, J., T. Mitchell, and C. Deser, 1989: The influence of seasurface temperature on surface wind in the eastern equatorial Pacific: Seasonal and interannual variability. J. Climate, 2, 14921499, doi:10.1175/1520-0442(1989)002<1492:TIOSST>2.0.CO;2.

Webster, P., and R. Lukas, 1992: TOGA COARE: The Coupled Ocean-Atmosphere Response Experiment. Bull. Amer. Meteor. Soc., 73, 1377-1416, doi:10.1175/1520-0477(1992)073<1377: TCTCOR $>2.0 . C O ; 2$.

Weiss, J., 1991: The dynamics of enstrophy transfer in two dimensional hydrodynamics. Physica D, 48, 273-294, doi:10.1016/ 0167-2789(91)90088-Q.

Yi, J., Y. Du, Z. He, and C. Zhou, 2014: Enhancing the accuracy of automatic eddy detection and the capability of recognizing the multi-core structures from maps of sea level anomaly. Ocean Sci., 10, 39-48, doi:10.5194/os-10-39-2014. 